\title{
3D Applications in Conservation and Connoisseurship: Investigating and Supplementing the Scholarly Catalogues of the Red Faun
}

\author{
ANGELA M. RATIGAN, Ruprecht-Karls-Universität, Germany
}

Focusing on the Capitoline Red Faun, this paper concerns the 3-dimensional digital model (3DDM) and its potential utility in creating accurate conservation condition reports. Traditional condition reports verbally express information about the state of a work of art, such as its preservation or past restorations, and are often supplemented with photographs or drawings. The various historical catalogues that have appraised the condition of the Capitoline Red Faun, more aptly referred to as "scholarly catalogues," demonstrate the potential for ambiguity within this practice; of the five accounts appraising the state of the Red Faun, no two agree on which parts are ancient and which belong to the eighteenth-century restorations of Bartolomeo Cavaceppi and Clemente Bianchi. Given that this sculpture is included within the art historical canon of Hellenistic sculpture, a new condition report is timely. This paper undertakes an exhaustive analysis of the various joins and offers another condition report, this one illustrated with an interactive, annotated 3DDM. When served to the public and scholars alike, these interactive condition reports can act as a critical tool, garnering interest in and facilitating re-appraisals of statues such as the Capitoline Red Faun.

Key words:

Scholarly Catalogues, Restoration, Sculpture, 3D modeling

SDH Reference:

Angela M. Ratigan, 2017. 3D Applications in Conservation and Connoisseurship: Investigating and

Supplementing the Scholarly Catalogues of the Red Faun, SDH, 1, 2, 123-164.

DOI : $10.14434 / \mathrm{sdh} . \mathrm{v} 1 \mathrm{i} 2.23579$

\section{INTRODUCTION}

In recent years professionals in the fields of archaeology, art history, and conservation have taken special interest in the three-dimensional digital model (3DDM), and many museums have begun exploring the advantages of incorporating 3-dimensional scanning and data capture into the conservation of artifacts [Wachowiak and Karas 2009, 142]. Though not yet a widespread practice in conservation, as more professionals in the fields of cultural heritage research and conservation begin exploring 3-D data capture, the technology could become an indispensable tool for research and

Special thanks are due to the Gerda Henkel Foundation (Dusseldorf, Germany) for their generous support in the final stages of this work.

Author's address: Angela M. Ratigan, Ruprecht-Karls-Universität, Institute of Classical Archaeology, Marstallhof 4, D-69117 Heidelberg, Germany; email: ang.ratigan@gmail.com

Permission to make digital or hardcopies of part or all of this work is granted without fee according to the open access policy of SDH.

(C) 2017 SDH Open Access Journal

Studies in Digital Heritage, Vol. 1, No. 2, Publication date: December 2017 
illustration. ${ }^{1}$ Taking as a case study the Red Faun (Fig. 1), the present paper concerns the 3DDM, its place within the historical dialogue of scholarly catalogues, and its potential utility in the creation and dissemination of condition reports.

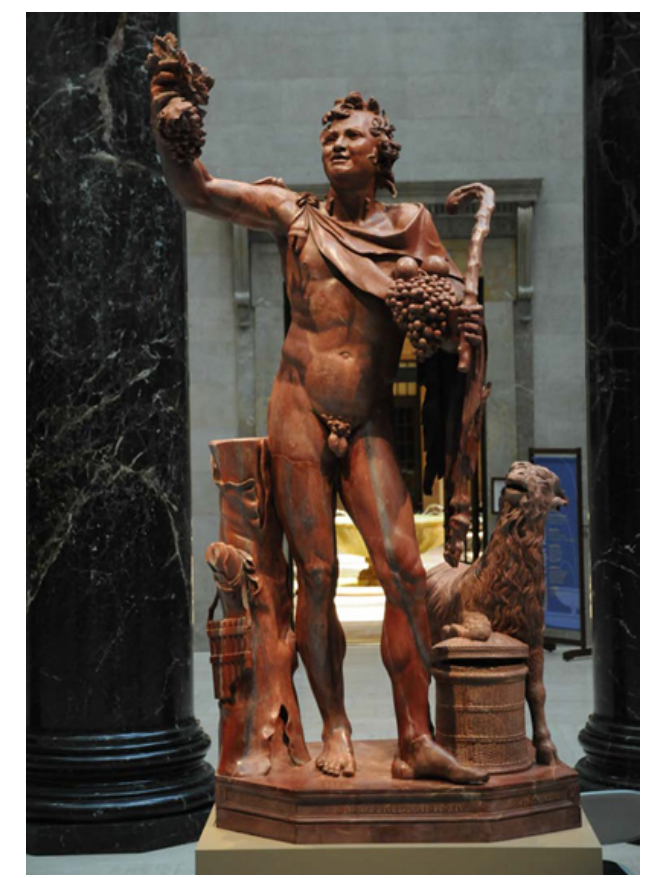

a)

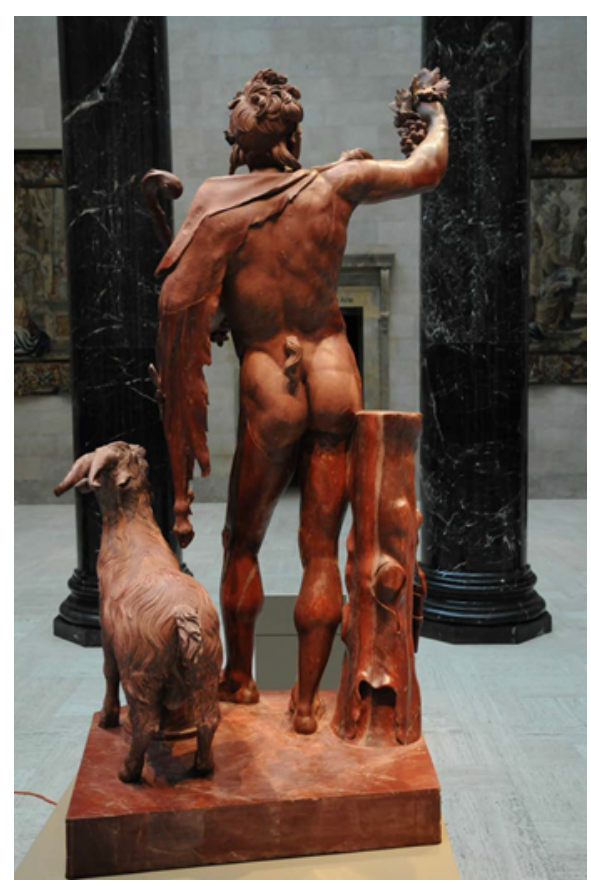

b)

Figure 1. The Capitoline Red Faun: a) front; b) back.

Three-dimensional digital models can serve many purposes within cultural heritage research-a fact to which an ever-increasing body of scholarly research can attest-but this paper will focus specifically on the advantages of supplementing traditional scholarly catalogues with annotated 3DDMs. These catalogue entries have steadily evolved into scientific condition reports authored by professional conservation specialists. Typically, the latter reports are written documents that assess the material state, or condition, of the object and are often supported with photographs or drawings. Both can lack clarity for a variety of reasons, including insufficient photographic coverage, imprecision of descriptive language, and ambiguity in the relationship between the verbal description and the related photographic illustration. Modern condition reports often include text and image, and while photographs are directly marked up with hatched line or stippled drawings, the image is referred to cursorily within a description [Masini 2014, 53-55]. Without doubt, condition reports listing and illustrating only the major conservation issues are sufficient for many objects in museums, and it is not possible for conservation scientists to perform such an exhaustive procedure

\footnotetext{
${ }^{1}$ For a separate discussion of the advantages of 3-D digital models, see [Frischer 2015]. Frischer weighs the advantages of the 3DDM against other forms of representation, such as casts, photographs, and drawings.
} 
as that discussed here on each object that passes through their hands. In this paper, we will show that when objects are selected for special study, and when scholars and conservation scientists work together to understand restoration, damage, or other material concerns, 3DDMs can usefully supplement the condition report and be disseminated so as to share the results of privileged close observation. As an example, the current project takes the eighteenth-century restorations of the socalled Red Faun, a sculpture that occupies a prominent position within the canon of Hellenistic art and that has been the subject of several inquiries regarding its restoration. Although these accounts were published in scholarly catalogues, not conservation reports per se, they can serve here to demonstrate the ambiguity of all such reports and in so doing highlight the advantages of offering a 3-dimensional, digital alternative. As a complement to the study here, the 3DDM is available online at https://skfb.ly/ULMr (Fig. 2), annotated with links to the pertinent photographs.

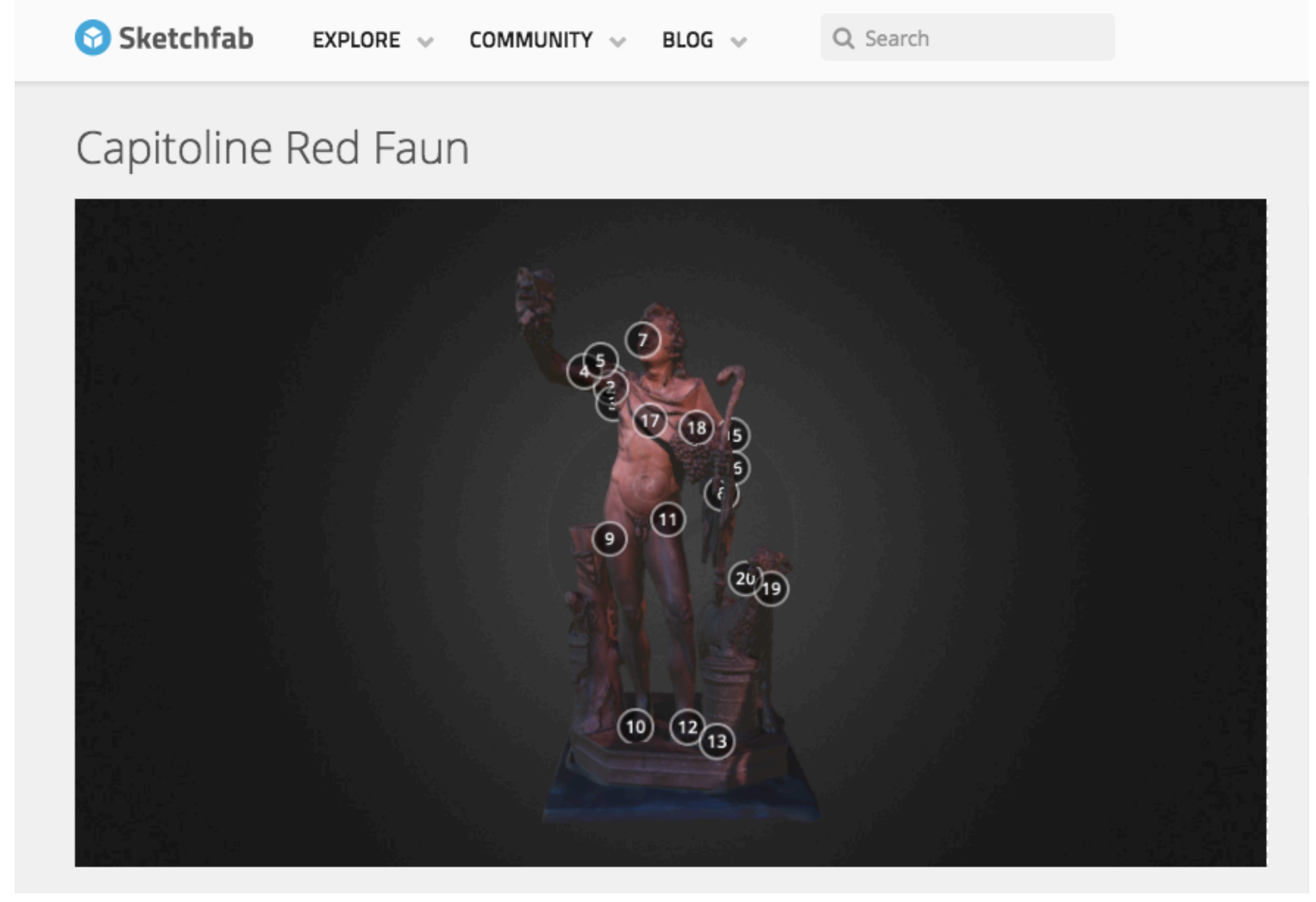

Figure 2. Screenshot of the annotated 3DDM on Sketchfab. The circles with numbers are called "annotations" in Sketchfab's parlance. Clicking on them opens a box in which will be found a link to the related closeup photograph taken by Robert Cohon. Note that the annotations can be turned off by clicking the Settings wheel icon and then clicking on Annotations/Hidden. 


\section{1:126 A. M. Ratigan}

\section{CONDITION REPORTS: A SHIFTING PARADIGM}

Today the conservation and restoration of architecture, sculpture, painting, and other categories of the arts encompass a set of scientific and regulated procedures and best practices. Various types of reports are written whenever an object is accessioned, loaned, or conserved, but the report with which this paper is concerned is the "condition report." A condition report is a statement that describes the object (dimensions, materials, and techniques) and its present condition (deterioration or past conservation/restoration), sometimes making recommendations for future treatment. Each museum follows its own standards in condition reports, and even within a single museum inconsistency can exist across a conservation department. Recognizing this problem, in 2007 the Victoria and Albert Museum created a new position (Condition Reporting Administrator) within their conservation department in order to standardize the process of condition reporting and to alleviate some of the burden on the various conservators [Nodding et al. 2008, 32]. One of the results of this campaign for improved condition reporting was efficiency "achieved by moving away from traditional handwritten descriptions, drawings, and acetate overlays, towards electronic condition statements based on high quality digital photographs."

In 2011, the Los Angeles County Museum of Art (LACMA) tested the viability of using iPads to directly mark-up digital photographs in conservation reporting [Posilev 2011, 11-13]. The conservation department had previously used written reports supplemented by photographs with transparent overlays to make notes on top of the photo without affecting the photo directly. LACMA's conservation department adopted one iPad to explore the advantages and shortcomings of creating reports directly on digital photographs. While the image size of the digital photographs and its lack of USB port were deemed a disadvantage, the iPad facilitated the annotation of digital photos and so continued to be used by staff every day; three more iPads were then added to the conservation department.

Responding to the widely felt need to improve the contribution of digital tools to conservation science, the Getty Conservation Institute (GCI), too, set out to propose a new paradigm "for the way data are collected, stored, accessed, shared, analyzed and interpreted" [Patterson and Trentelman 2013 , 4]. The report outlined the potential benefits of integrating various types of data into conservation reports, and these included the potential for increased scholarship and a broadened audience based on new means of communication. With a case study of the condition report of Jan van Eyck's Ghent Altarpiece, the GCI demonstrated how web applications could serve macrophotographs, reflectography, X-radiography, and dendrochronology to the public and specialists alike by publishing the high-definition images along with conservation and research reports on the web [Patterson and Trentelman 2013, 12]. The GCI report states that the website has achieved popularity as a classroom teaching aid and a reference for specialists, and there are plans to add to the website as the painting is restored.

\footnotetext{
${ }^{2}$ Digital photography and condition reporting has also eliminated redundancy in loaning practices at Colchester and Ipswich Museum Service, which loans on average twelve works per year. Before digitization, the condition report and sketches of the work had to be created each time the object was sent to another museum. Now the images and report are digitized, can easily be printed and the repetition eliminated [Entwistle 2008, 46-48].
} 
The increased use of photographic evidence in condition reporting is one method to avoid the ambiguity of verbiage, in particular for 2-dimensional works of art, but if these reports should aid in the attributive and philological study of sculpture, then they must be improved upon. 3-dimensional works of art pose a particular set of problems with respect to photographic documentation, because, as Wölfflin observed with regard to the Baroque, sculpture "cannot be tied down to a particular view" [Wölfflin 1950, 54]. Condition reports of three-dimensional works such as the Red Faun would do better to contextualize photographs of pertinent details using clickable hotspots, or annotations, within a 3DDM. The web-published, annotated 3DDM is the most precise and efficacious documentation of the condition of a 3-dimensional work of art, bearing the additional but no less important advantage of aiding the remote scholar in his study of the object, just as the GCI web report on the Ghent Altarpiece demonstrated. That the newly published Oxford Handbook of Roman Sculpture includes a chapter on 3-D scanning and modeling demonstrates the growing interest and positive reception of new technologies by many scholars in the fields of archaeology and art history [Frischer 2015]. The manifold advantages of 3-D technologies will continue to accrue as various methods and applications are tested, such as in this study.

\section{THE RED FAUN IN THE CANON OF ART HISTORY}

As a case study, the Red Faun and its many historical "condition reports" demonstrate the potential for a lack of clarity in verbal descriptions. This paper cites five such accounts of the condition of the Red Faun that, through their disagreements and ambiguity, underline the necessity of disseminating the condition reports of studied 3D objects as 3DDMs to scholars. Before proceeding to the five verbal accounts and ultimately to my own observations and 3DDM, it is useful to discuss the Red Faun as it appears today to highlight what is at stake in this argument.

The so-called Red Faun, despite its appellation, is a sculpture depicting a satyr. Called "red" after the rosso antico marble from which it was carved, it is a textbook example of late Hellenistic sculpture, praised for its lithe proportions, expressive gesture, and the craftsmanship of its execution [Smith 1991, 129]. Today the satyr stands with his weight resting on his right leg, leaning slightly on a tree trunk over which a syrinx (or pan flute) hangs, while the left leg balances gently on the outside of his left foot. His hips tilt accordingly, creating a sinuous curve throughout the torso. In his upraised right hand he holds a bunch of grapes, a bounty at which he casts his jubilant gaze, parting his lips in a smile. A goatskin is tied at his right shoulder, and the folds that fall over his chest leave a depression between his torso and left arm, where the Red Faun carries another bunch of grapes and two pomegranates. He holds a pedum, or shepherd's crook, in his left hand. To his left, the goat rests his right leg atop the lid of a basket of fruit, dislodging it to reveal the fruit inside. The Red Faun's companion goat tilts its head up to the Red Faun with its mouth open in a bleat; the facial expressions of the two are comically similar and suggest a certain level of similarity in their temperaments. Satyrs were imagined as half-human woodland creatures in the thiasos (retinue) of the god Dionysos, or Bacchus, whose sphere of influence extended from wine to harvest, festive revelry, and ritual madness.

Though this sculpture is often cited in surveys of ancient art, art-historical treatments of the Red Faun have acquired a tone of skepticism in recent years as some scholars have expressed misgivings

Studies in Digital Heritage, Vol. 1, No. 2, Publication date: December 2017 
about the statue's state of restoration [Ramage 2002, 61-77]. As a result, some doubt has been cast on its authenticity as a Hellenistic sculpture, and its place in the canon of art history is therefore at stake. According to the inscription on the base, Pope Benedict XIV donated the sculpture to the Capitoline Museums in 1746, just two years after Bartolomeo Cavaceppi, with the help of Clemente Bianchi, began the restorations [Barberini and Gasparri 1994, 23-25]. Together they completely refashioned the fragments into what we now call the Red Faun, responding appropriately to the demands of an eighteenth-century patronage whose tastes favored the whole statue [Dallaway 1800, 272-273], a tendency that Riegl termed "newness value" in 1903 [Riegl 1903, 54]. Cavaceppi thereafter developed a proclivity for re-purposing fragments of ancient sculpture into a new whole, winning himself many commissions over his long career and, today, a reputation for imaginative restorations. If evidence proves that the restoration was excessive or without precedent, this restored sculpture could be interpreted as an artifact of the eighteenth century, divorced from the artistic intent of the ancient sculptor. The evidence here is gleaned by naked-eye observation and discernment of what is ancient from what is restored, and it is then communicated via a detailed catalogue of breaks and joins and a supplemental 3DDM. The condition of the Red Faun (and of any ancient sculpture restored in the eighteenth and nineteenth centuries) has implications relevant to the fields of Classical archaeology and art history, so new observations must be served to experts in these fields in order that the statue and its inclusion within the canon of Hellenistic art be appraised anew, breaks and all.

\section{CATALOGUE ENTRIES OF THE RED FAUN}

The following five scholarly catalogues represent individual efforts to take inventory of what fragments of the Red Faun are original or restored. These reports are exercises in the tradition of connoisseurship, and as some of them antedate the conservation practices of today, they are being termed "condition reports" retroactively and somewhat loosely, since most should more properly be called catalogue descriptions. They are here addressed in chronological order, are supplemented by a photograph edited to illustrate the appraisal of the respective author, and are followed by a chart that cross-references their observations. This graphical representation will highlight the ambiguity and subjectivity of the verbal condition report.

The earliest description of the Red Faun was discovered among the papers of Marquis Capponi and date to 1736, which Barberini first published in 1994 (Fig. 3). Several passages taken from Capponi's records reveal the complex circumstances under which the Red Faun was restored. He writes, "On the $21^{\text {st }}$ of the month, Gio[vanni] Migliore, quarryman and a good citizen of Tivoli, brought to me from a quarry you own, far from the above-mentioned city, a torso of the statue of a faun, a little less than life-size, [preserved] down to its groin with its head attached, and with bunches of grapes and fruits on the left flank but missing the arms, thighs, legs. Although he brought a piece of the leg and a thumb, everything made from rosso antico marble and in a most beautiful style, so much so that [I would assert that], if he found the rest, it would be something considerable...". It appears that most of the upper body of the Red Faun is antique, with the exception of the arms, and the lower half is restored. But the picture becomes more complex as Barberini cites further passages.

Studies in Digital Heritage, Vol. 1, No. 2, Publication date: December 2017 
According to Capponi, another excavator, Furietti, found additional pieces of the Faun and made a gift of them to Pope Benedict XIV in 1744, who then requested that Capponi make arrangements for a restoration of the collection of pieces. He writes in April 1744 that he assembled experts at his home to "learn their opinion about the restoration... of the Red Faun found in 1736 in Hadrian's Villa in Tivoli..." [Barberini and Gasparri 1994, 24], but was dissatisfied with the effort. Capponi hired the services of Salvatore Ettore, a painter and antiquities enthusiast, to draft two drawings in red pencil of the torso, bust, and "the small pieces sent to me here in my house by His Holiness Benedict XIV. The pieces numbered over 22-almost like tiles-and contained half a head and a half of the base of the aforementioned figure" [Barberini and Gasparri 1994, 24]. This last sentence indicates that, while the head was attached when Capponi received the statue at first, it was not the entire head; some of it was sent from the Pope.

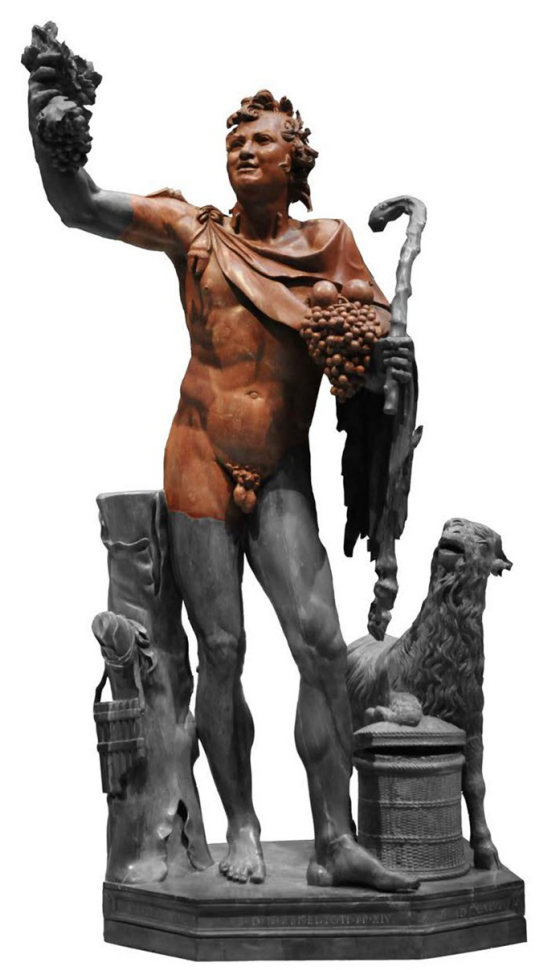

Figure 3. The Red Faun edited to illustrate Barberini's reading of Capponi's account. Antique fragments in color, restorations in grayscale.

The next reports are written first-hand by the observer. In 1891, Wolfgang Helbig published a guide to the public collections of Classical antiquities in Rome (Fig. 4) [Helbig 1891, 397]. In his description of the Red Faun, he wrote:

Satyr of red marble (rosso antico). Found in 1736 by Furietti in Hadrian's Villa on the Tibur, donated to the museum by Benedict XIV in 1746. Added are the tip of the nose and chin, slivers of hair, the right arm with the bunch of grapes, the left hand with the pedum, the hanging 
portion of goatskin, the legs-although the feet are partly antique-the trunk with the syrinx [reed pipe]; on the goat, the head, the left foreleg and both hind legs; various parts of the plinth [Helbig 1891, 397]. ${ }^{3}$

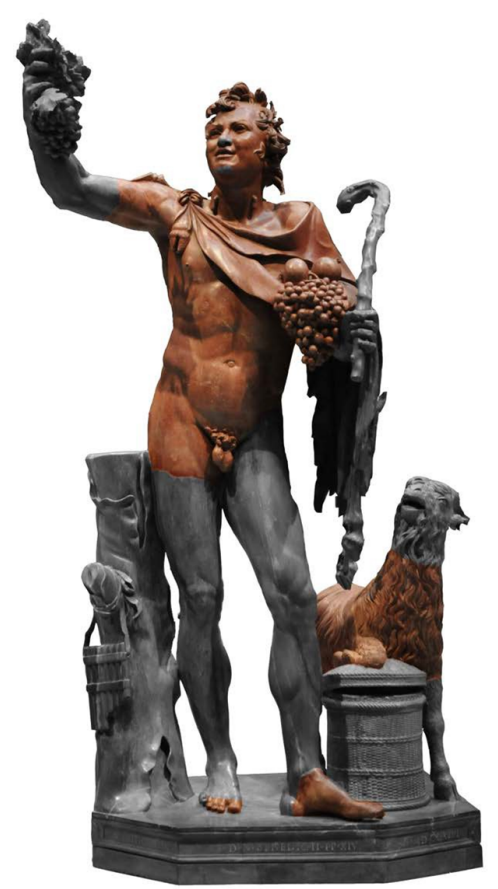

Figure 4. The Red Faun edited to illustrate Helbig's account. Antique fragments in color, restorations in grayscale.

Like Helbig, H. Stuart Jones' 1912 account catalogues the restorations (Fig. 5) [Jones 1912, 309]. His entry reads as follows:

Satyr of Rosso Antico. H. 1.675 m (from r. hand). Marble, rosso antico. Restored: Small pieces of nose, lips, and chin, many locks, tip of l. ear, r. arm with grapes from middle of upper arm, 1 . hand and pedum. R. leg from upper part of thigh down to and including heel, whole l. leg from groin to heel and tips of three toes of l. foot, a fold of goatskin on the chest and the part hanging free below. L. arm, with elbow, pieces of the fruit, the support, and practically all the plinth. Of the goat, head, neck, and part of chest, hind legs and tail.

\footnotetext{
${ }^{3}$ Translated by the author from the German original, which reads: Satyr aus rothem Marmor (rosso antico). Gefunden 1736 durch Furietti in der tiburtiner Villa des Hadrian [Ficoroni bei Fea Miscellanea I p. CXLIV n. 55], 1746 von Benedict XIV. dem Museum geschenkt. Ergänzt die Spitze der Nase und des Kinnes, Splitter am Haare, der r. Arm mit der Traube, die l. Hand mit dem Pedum, der herabhängende Theil des Ziegenfelles, die Beine-doch sind die Füsse zum Theil antik-, der Stamm mit der Syrinx; an der Ziege der Kopf, das l. Vorderbein und beide Hinterbeine; vielerlei an der Plinthe.
} 


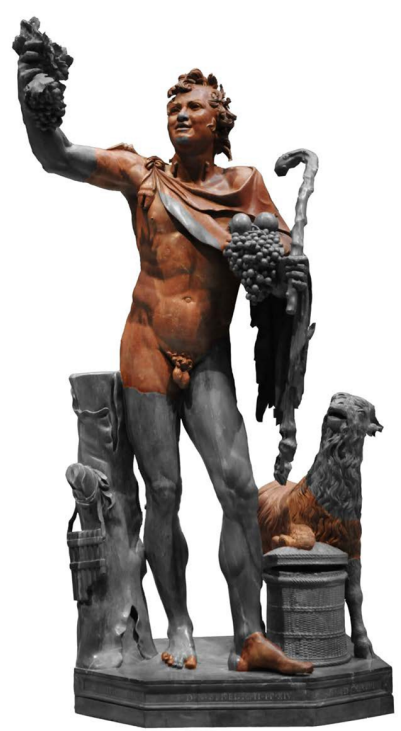

Figure 5. The Red Faun edited to illustrate Jones' account. Antique fragments in color, restorations in grayscale.

The fourth report was published in 1958 by Seymour Howard (Fig. 6). His appraisal questions which portions are antique and corroborates much of Barberini's understanding of Capponi's report of the delivery of the fragments in 1736 . Howard writes briefly that "the torso and head, the left arm to the wrist, the body of the goat, and the basket of fruit" are antique.

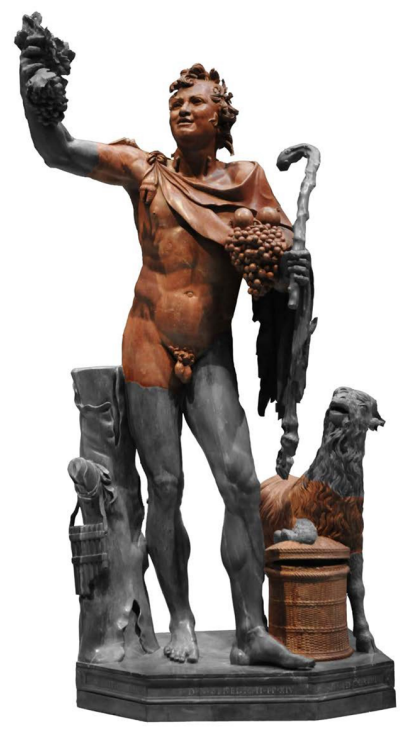

Figure 6. The Red Faun edited to illustrate Howard's account. Antique fragments in color, restorations in grayscale. 
The fifth, and most recent, report comes from the 1983 dissertation of Joachim Raeder on sculpture from Hadrian's Villa (Fig. 7) [Raeder 1983, 65]. ${ }^{4}$ He describes the restorations of the Red Faun as follows:

Material: Rosso Antico. Height including the raised arms $1.675 \mathrm{~m}$. State of preservation: added are the small piece of the nose, the lip and the chin, many locks of hair, the tip of the left ear, the right arm with the bunch of grapes from the middle of the upper arm, the left hand with the pedum, the right leg with almost the whole upper leg down to the ankle, the entire left leg from the groin to the ankle, three toes of the foot, the free-hanging piece of the goatskin, part of the fruit, the support, the basket and most of the plinth; on the goat the head, the neck, a piece of the chest, the back legs and the tail are added.

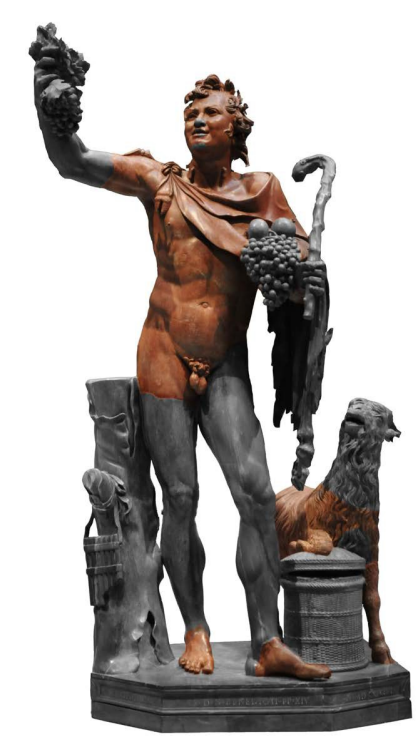

Figure 7. The Red Faun edited to illustrate Raeder's account. Antique fragments in color, restorations in grayscale.

In reading through the reports, it becomes increasingly difficult to parse out which reports confirm or negate the claims of another; thus the most obvious observation one can make about the preceding condition reports is that they are general, ambiguous, and subjective, some privileging the "bigger picture" and neglecting the details. To facilitate the understanding of these divergent data, each observation was consolidated onto a single table (see Table 1 below). The terms in the first column

\footnotetext{
${ }^{4}$ The original German text reads: "Material: Rosso antico. Maße: H. einschließlich des erhobenen Armes $1.675 \mathrm{~m}$. Erhaltungszustand: ergänzt sind kleine Stücke der Nase, der Lippen und des Kinns, viele Locken, die Spitze des linken Ohres, der rechte Arm mit der Traube von der Mitte des Oberarmes an, die linke Hand mit dem Pedum, das rechte Bein mit fast dem ganzen Oberschenkel bis zur Ferse, das ganze linke Bein von der Leiste bis zur Ferse, drei Zehenspitzen des linken Fusses, die frei hängenden Teile des Ziegenfells, Teile der Früchte, die Stütze, der Korb und fast die ganze Plinthe; bei der Ziege sind der Kopf, der Hals, ein Teil der Brust, die hinteren Beine und der Schwanz ergänzt."
} 
correspond to the words used in the reports. Those spaces marked in green and red relate to assessments of the antiquity or modernity of the fragment, respectively, while a pattern overlay demonstrates that the author elaborated on the state of the feature (leg, plinth, arm, etc.). For instance, Jones wrote that "pieces of fruit" on the nebris or "practicallyall the plinth" are restorations, implying that other parts of the fruit and plinth are antique. Thus, the corresponding places on the table are marked with a pattern. All those spaces within the table that are left blank demonstrate a gap in data-the author did not mention the respective fragment. How one is to interpret this absence is a matter of debate: is the blank evidence of the contrary in absentia, or did the author overlook the fragment because he did not study it closely? If we take the gaps as evidence of the contrary, then the unmentioned fragments in the "Barberini" column could be interpreted as "modern" because, in neglecting to make note of them, the account suggests they are not antique. This same principle could be applied to the other condition reports.

The chart also facilitated the identification of several points of conflict. One locus of disagreement is the left arm. Jones writes that the left hand with the pedum and the elbow are restored, suggesting in the absence of any mention otherwise that the forearm is antique, while Howard observes that "the left arm to the wrist" is antique. Meanwhile, by excluding the left arm in their reports, Capponi would call the arm modern and Helbig and Raeder would assign it an antique date. Clearly, the potential for variability among written reports makes them less efficient. This exercise has demonstrated the ambiguity and subjectivity of the written condition report, but these are problems that conservation departments such as those mentioned above have recently begun to address with the increased use of photographic evidence and digitization. As became clear through the investigation of the above reports, the subjectivity of the human element has introduced complications to such assessments as condition reports, but it is in service to the enterprise of connoisseurship, that human attendance to condition and quality, that the following procedure is recommended and demonstrated in practice.

\section{ILLUSTRATING THE CATALOGUE}

The remaining discussion is a prescription for how one might go about cataloguing and communicating the results of the extensive study of a restored object such as the Red Faun. The methods and procedure followed here are particularly pertinent to the publication of 3-dimensional works of art because the 3DDM does not reduce the 3-dimensionality of the work to an immovable 2dimensional plane, as a photograph or drawing might. Certain advances in technology afford scholars of the $21^{\text {st }}$ century new opportunities to disseminate research observations that have been hitherto unknown or unexplored. Earlier publications of sculptures were limited by the 2dimensional format of the paper publication and the cost of printing color images and therefore did not facilitate interactivity or observation from multiple perspectives. 3-D data capture allows not only for the remote study of a sculpture in the round but also for sharing the privilege of close observation at low cost. Peers within the field can share in a proximity that, in the case of the Red Faun, would otherwise have only been possible with a trip to Rome and very possibly the permission of the museum. This is not to say that there is nothing to be gained from the physical presence of a work of art. Surely a 3DDM cannot reproduce the aesthetic experience that can only be enjoyed in actuality

Studies in Digital Heritage, Vol. 1, No. 2, Publication date: December 2017 
and without mediation [Bell 1996, 68]. ${ }^{5}$ The current endeavor is, however, not dedicated to aesthetic experience. My aim is instead to demonstrate how a 3DDM can aid a scholar or conservator in disseminating the most faithful condition report possible so that he and others can remotely appraise the work on any number of levels, with special reference to connoisseurship. This exercise is meant to help those who want to approach the work of art with erudition and intuition; it takes the work of sculpture as an historical document that must be subjected to meticulous study before it can be interpreted.

To be sure, the debate over the authenticity of the Red Faun is one of connoisseurship and attribution and centers on the question "does the sculpture belong in the repertoire of Hellenistic art or is it largely an artifact of eighteenth-century aesthetic values?" These are questions that only an expert with a mental stock of comparanda and material experience can address. Of course, in doing so, we are helped by the convenient fact that a second Red Faun that may be a pendant to the one we are discussing was also found at the villa. It is part of the collections of the Vatican Museum [Raeder 1983, 106-107]..$^{6}$

It is not our intention to undertake such a study here, but rather to keep the focus on the Capitoline Red Faun and note that even a cursory glance at color images of the Red Faun tells us that the sculpture is an assemblage of fragments, some ancient and others modern. The legs are sculptured from a different marble than the torso and ever more restorations become obvious after prolonged study. What is at stake in this argument is whether or not the Red Faun was restored in such a way as to faithfully represent the original sculpture. Such an interest in the original is bound up in the desire to understand artistic intent and, by extension, cultural milieu, and is the wellspring of lively debate within the conservation community. While it could be argued that artistic intent is irretrievable, this attitude is contrary to the human impulse to bridge the gap between past and present by making attempts to understand it despite the difficulty. Some restorations do overstep the affordances of the fragmented object; in such cases, the modern viewer is deceived, seeing the work of a conservator and yet believing it the work of a Hellenistic sculptor, for example. The job of the conservator is to strike some "balance between protecting the documentary information provided by a work of art's accrued historical value and ensuring that its aesthetic imperative, its demand to be appreciated aesthetically as a work of art, will be respected" [Talley 1996, 8].

The "accrued historical value" could refer to the wealth of archaeological, or "documentary," information imparted alone by the fragments that were found in Hadrian's Villa in 1736. Secondly, that the artistic intent, or "aesthetic imperative," be re-introduced into the fragments is a goal that requires cooperation between connoisseurship and conservation, since not only must the ancient parts be determined through comparanda and cultivated judgment, but they also must be restored with integrity.

\footnotetext{
${ }^{5}$ Bell writes that all copies lack the "significant forms" of the original. Therefore, the 3DDM, as a mediated instantiation of its antecedent, cannot induce aesthetic meditation.

${ }^{6}$ Vatican Museums, Pio Clementino, inv. 801. See also Benjamin's "The Work of Art in the Age of Mechanical Reproduction," wherein he wrote that only the original work of art could exude an authentic "aura." Copies and pendants lack the authority of the original and should be admitted as evidence with some caution.
}

Studies in Digital Heritage, Vol. 1, No. 2, Publication date: December 2017 
With respect to the Red Faun, it must be determined what is ancient in order to assess whether or not Cavaceppi and Bianchi took undue liberties in their restoration, liberties that compromise its merit relative to the artist's original intent. And so, after presenting a detailed report of the condition of the sculpture below, the debate will ultimately be put to the community of classical art historians and archaeologists in order that they might easily re-examine the sculpture and contribute their own appraisals of the restorations. Because the 3DDM is sustainable online for the long-term, it also preserves the current condition of the Red Faun for future generations to undertake similar study of the sculpture. ${ }^{7}$

\section{CATALOGUE OF RESTORATIONS}

The task of the following catalogue of observations is to study the Red Faun closely and to discern what is ancient and what is restoration. When the Red Faun travelled to the Nelson-Atkins Museum of Art in the summer of 2013, Robert Cohon, Curator of Ancient Art, took the opportunity to document each visible break with a photograph. Those photos, which number in the hundreds, have been made available to the author of this paper, and what follows is a record of the observations gleaned from those photographs. The joins are recorded with a prefix indicating location (e.g. the left arm is identified as 'LA'), followed by an enumerated suffix (e.g. the first catalogue entry for the left arm is "LA-1", the second "LA-2", and so on). As the earlier discussion of historical condition reports made evident, written condition reports are inherently ambiguous, do not allow for the reader to explore the sculpture outside the author's interests, and do not allow for remote interactivity. Taking the lessons of the museums discussed above into account, and taking advantage of new trends in 3D data capture, the catalogue is supplemented by an annotated 3DDM (available at https://skfb.ly/ULMr).

\footnotetext{
${ }^{7}$ For a discussion on the sustainable conservation and long-term maintenance of cultural heritage, see Meiling et al. 2011.
} 
Right Arm: almost entirely restored, shoulder composed of many fragments.

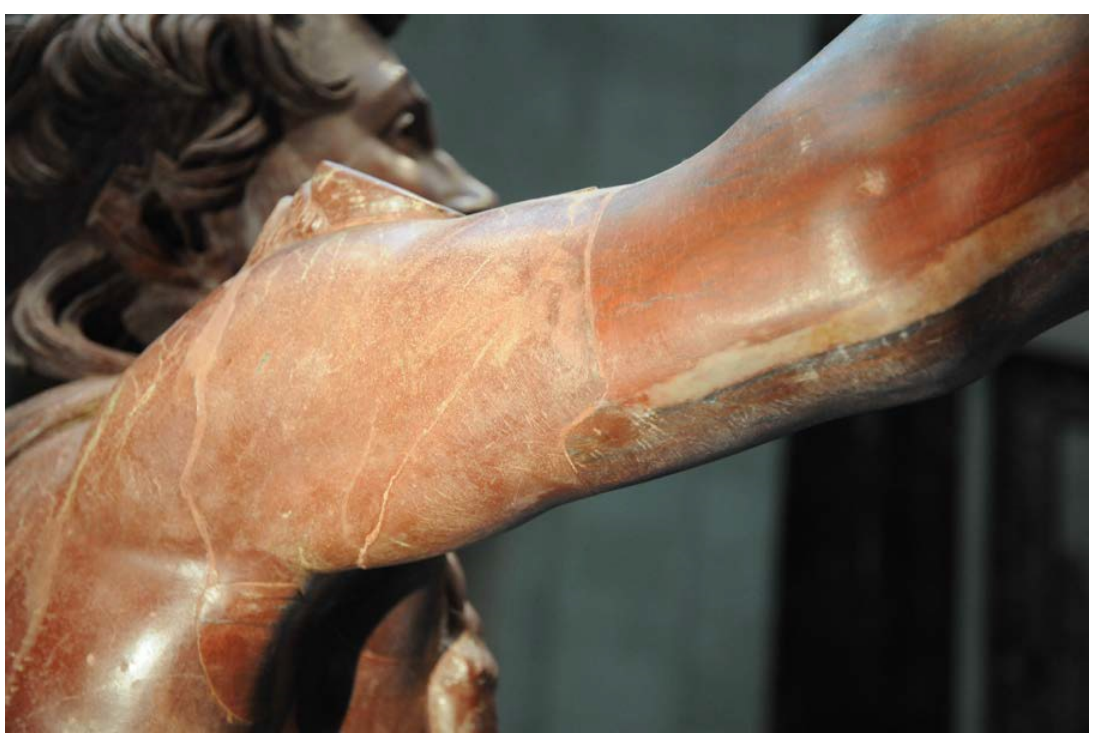

Figure 8. RA-1: Antique upper bicep. Mid-bicep up to and including the fruit is restoration.

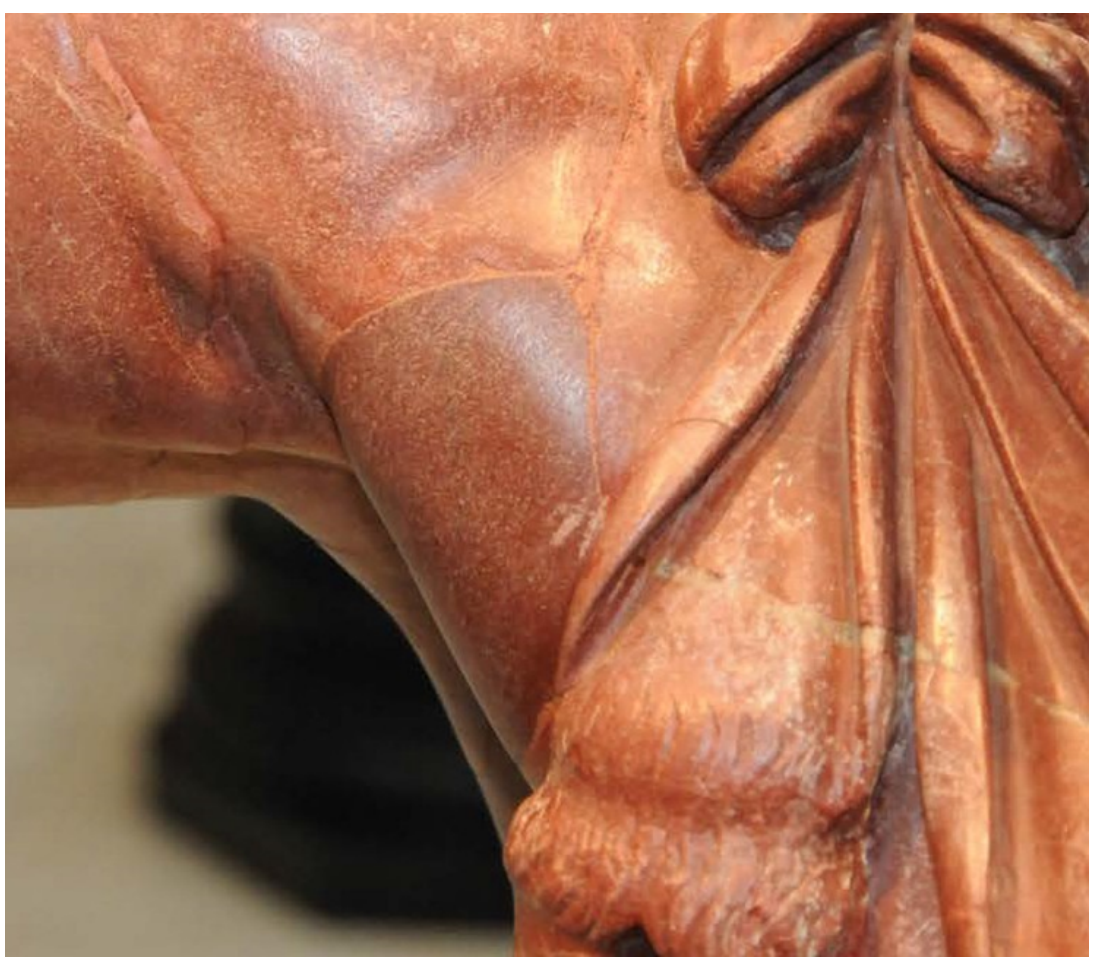

Figure 9. RA-2: Restored skin on the front of underarm. 


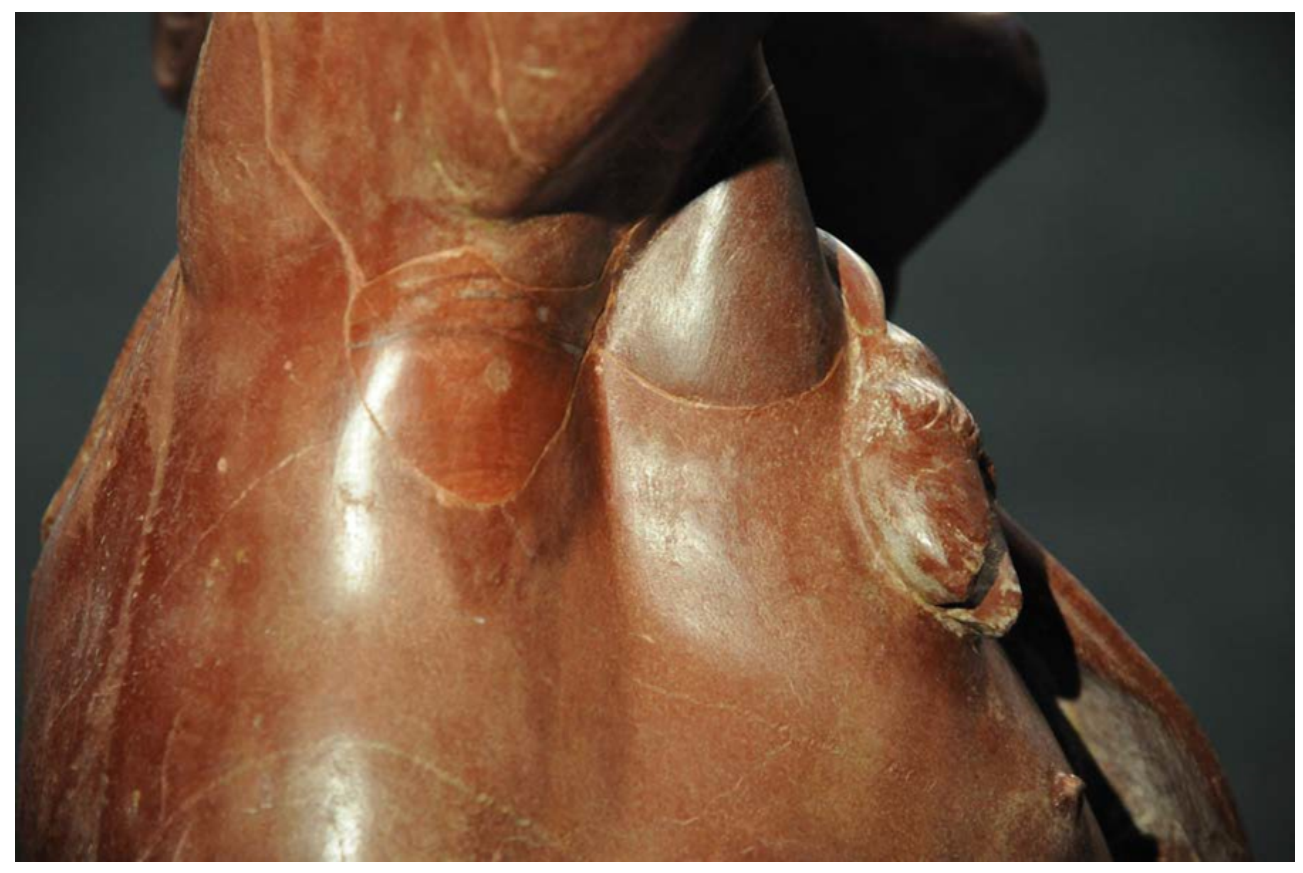

Figure 10. RA-3: Restored skin of lower underarm.

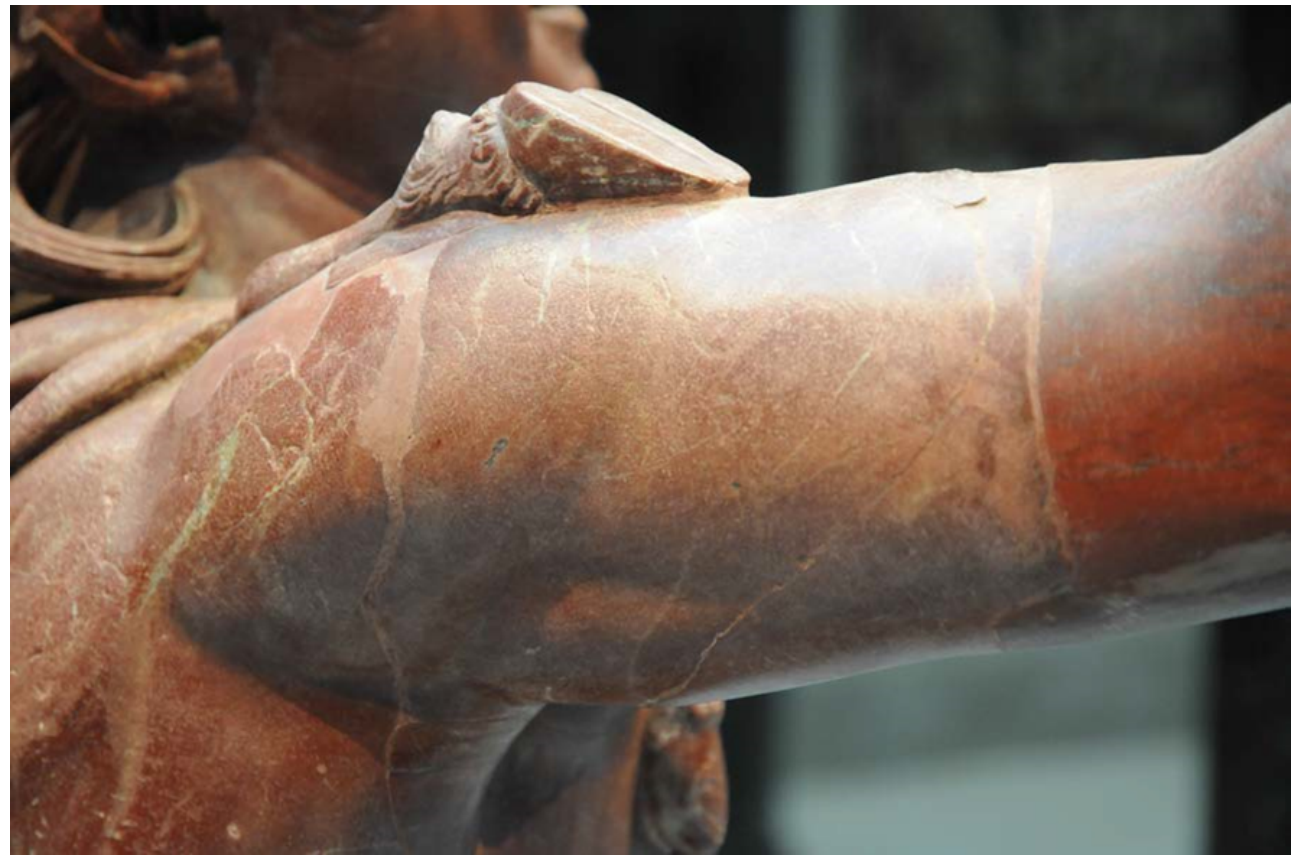

Figure 11. RA-4: Antique rear of shoulder and upper bicep (as noted in RA-1), but joined together by a significant amount of matte fill. 


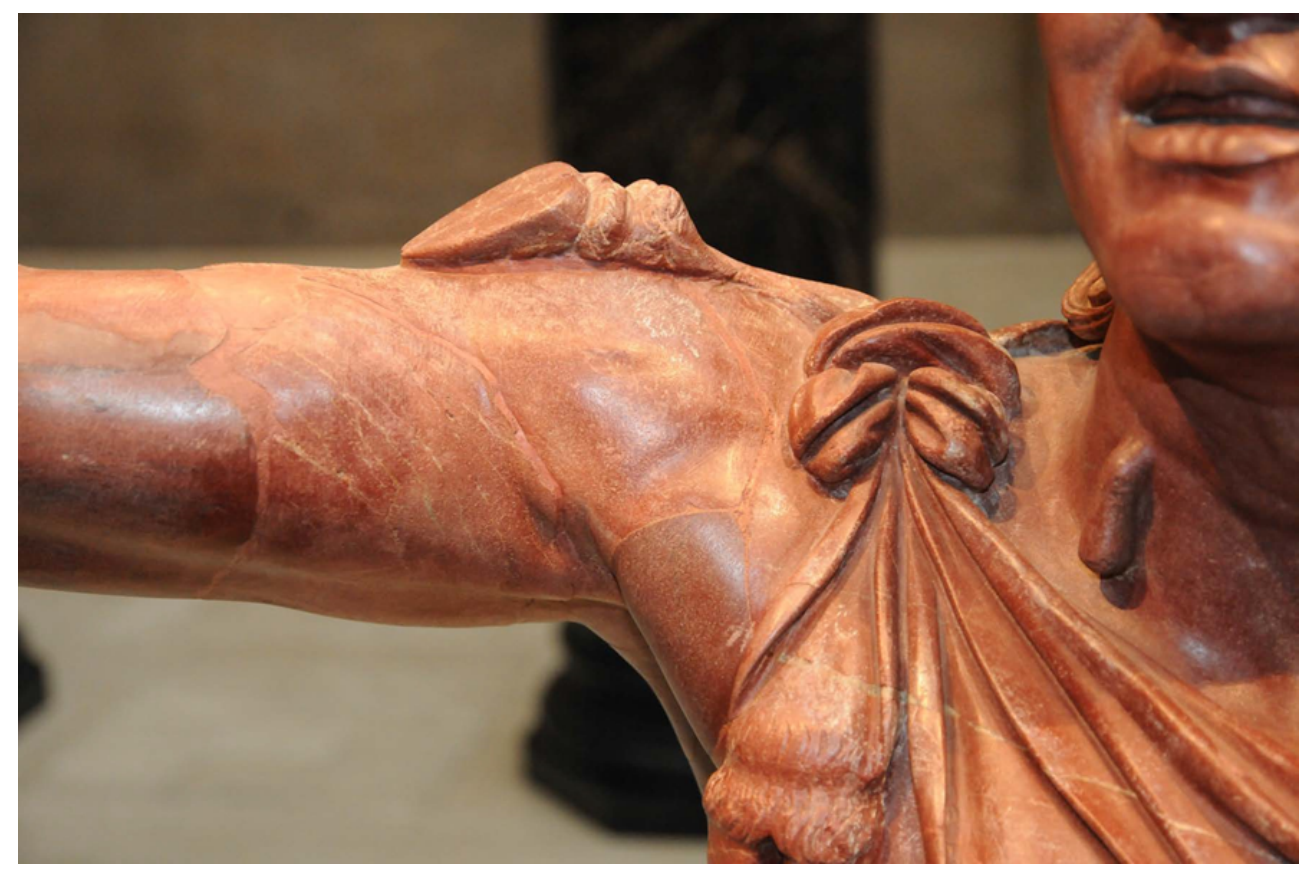

Figure 12. RA-5: Antique front of shoulder and upper bicep (as noted in RA-1), but the two are joined by a matte fill.

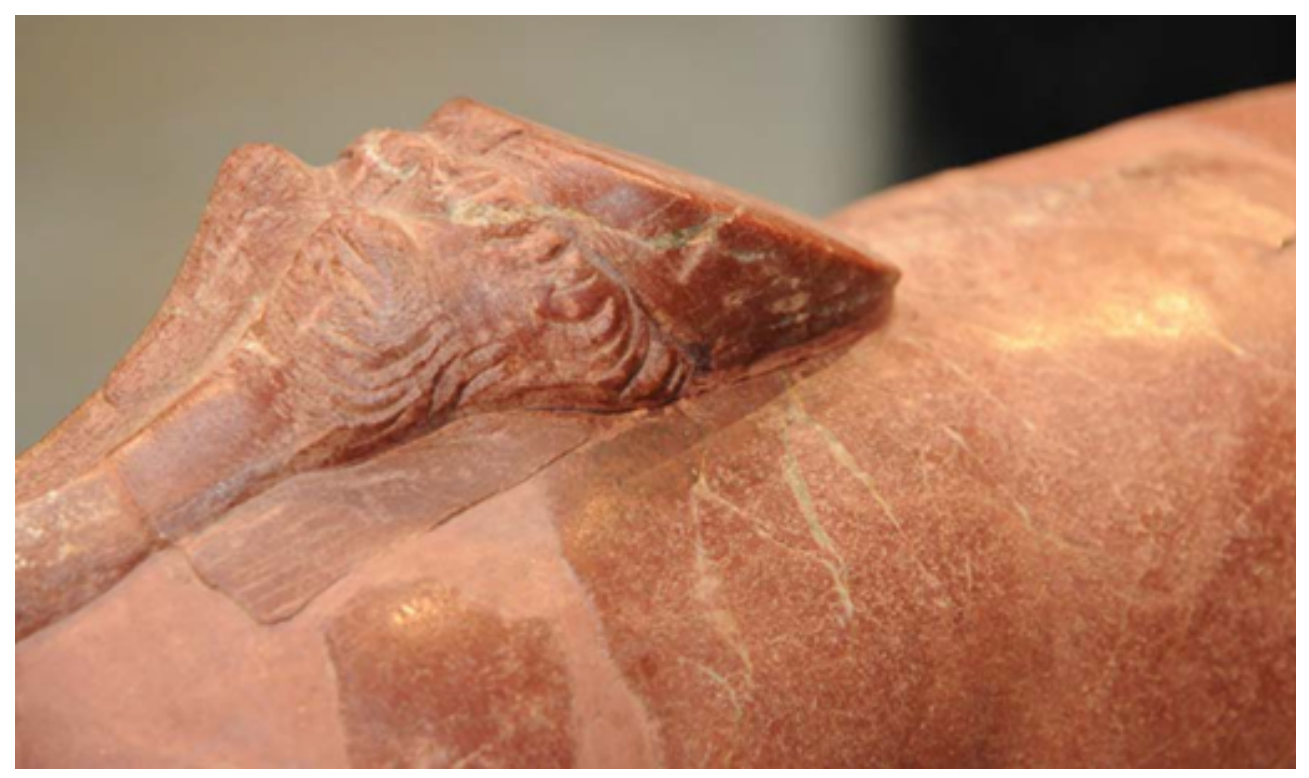

Figure 13. RA-6: Restored goat hoof attached to top of right shoulder with a significant amount of matte fill. 
Left Arm: antique forearm, elbow and hand restored.

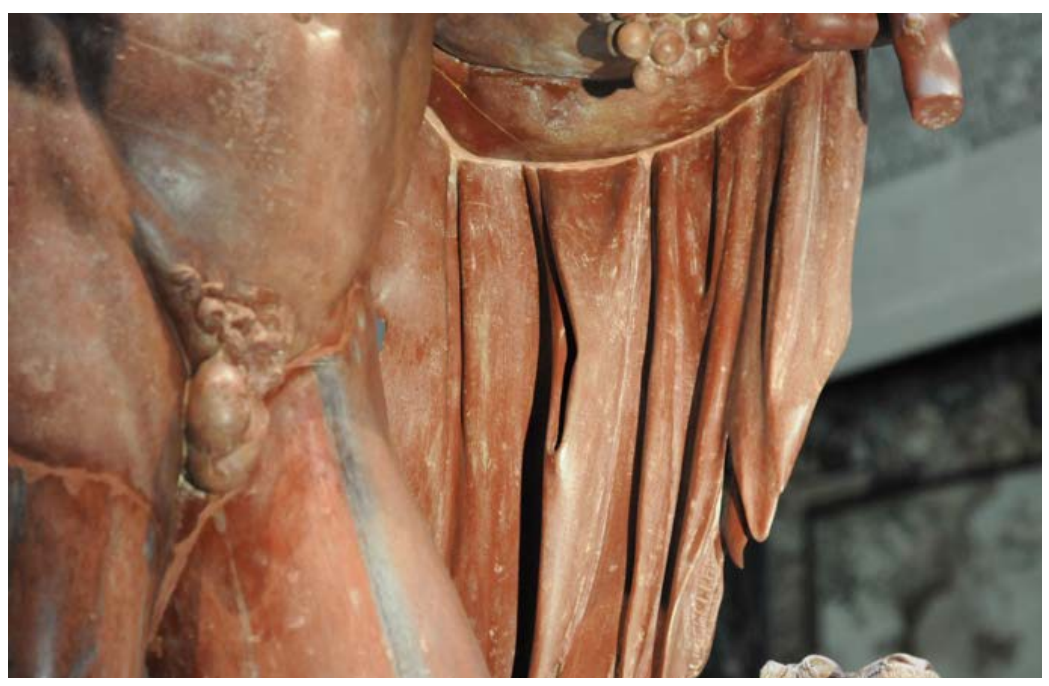

Figure 14. LA-1: restored left elbow, antique forearm. LA-2: restored left hand, antique forearm.

Head: almost entirely antique, small restorations.

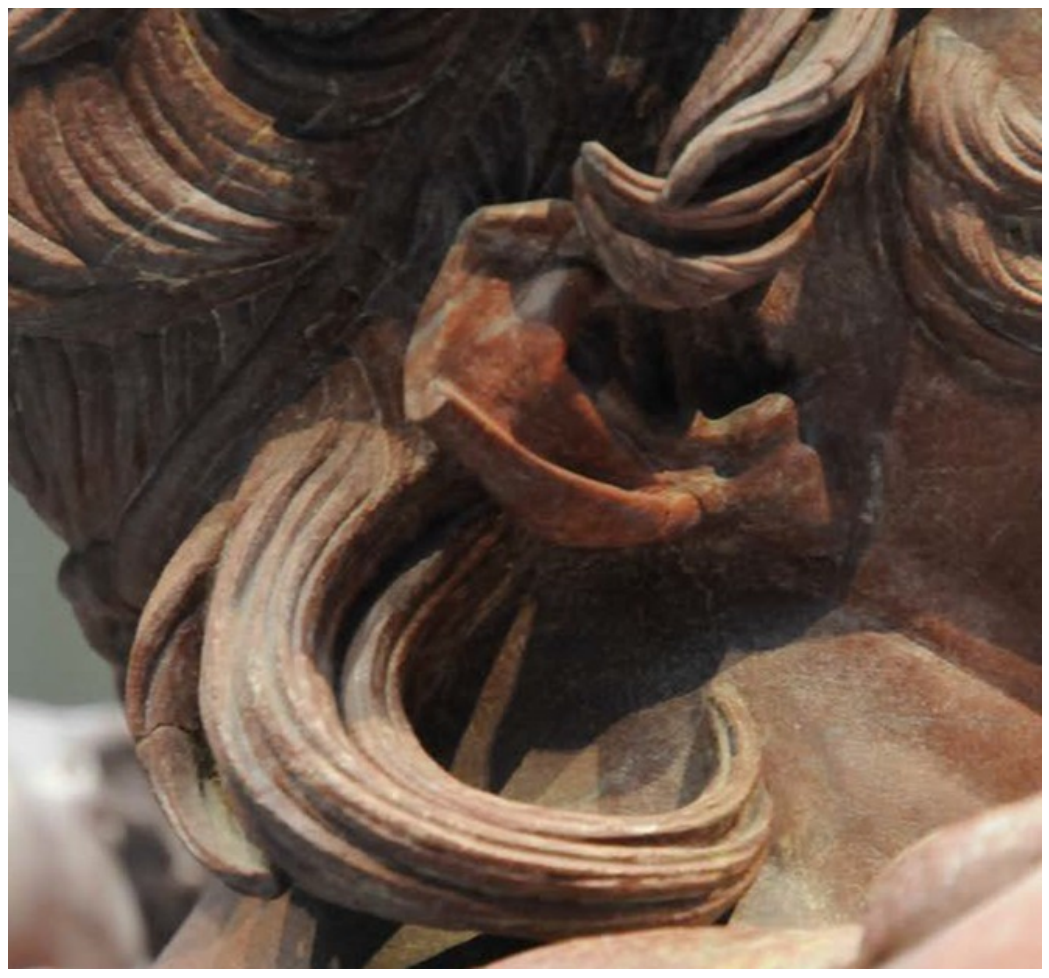

Figure 15. H-1: antique right earlobe and inner ear, restored upper cartilage. 
$1: 140 \quad$ A. M. Ratigan

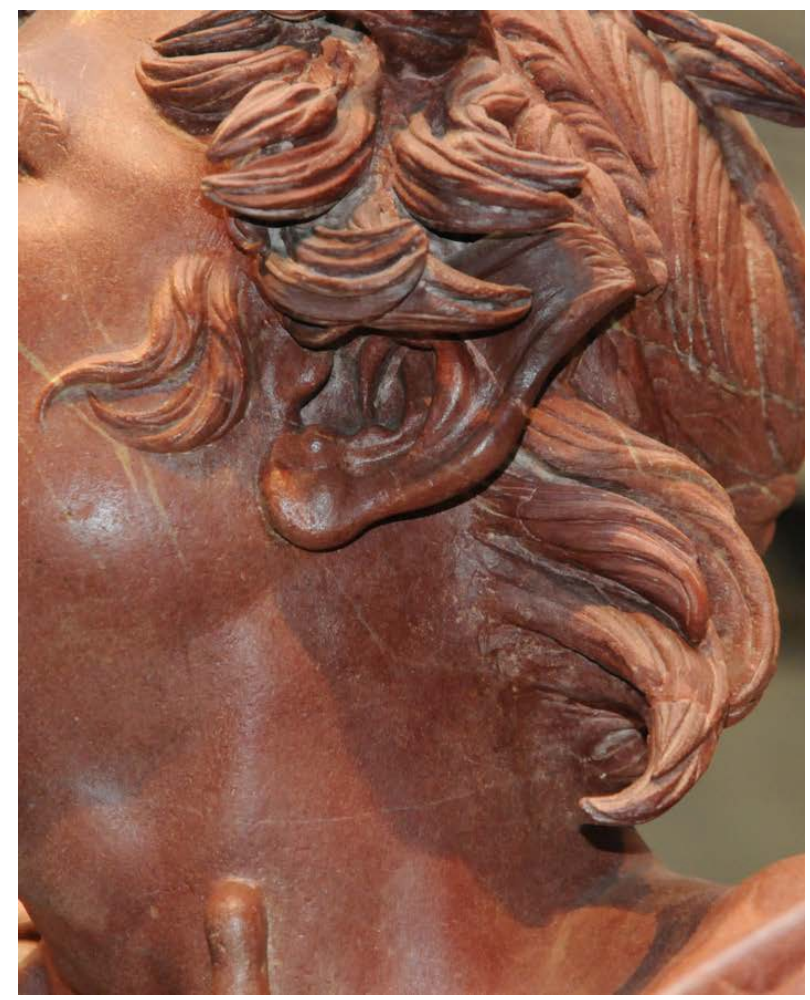

Figure 16. H-2: antique lower left ear; restored upper ear.

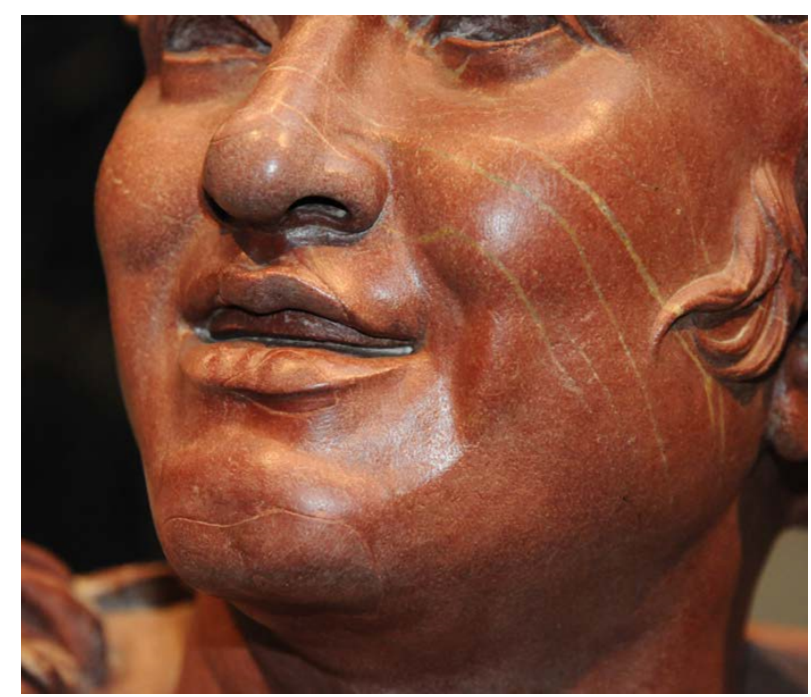

Figure 17. H-3: antique bridge of nose, restored tip. H-4: antique corners of upper lip, restored philtum and philtral ridge. H-5: much of lower lip antique, lower left portion restored. H-6: antique lower jaw, restored cleft chin. The locks of hair feature many joins, most of the tips of hair have been restored. 
Torso: ancient.

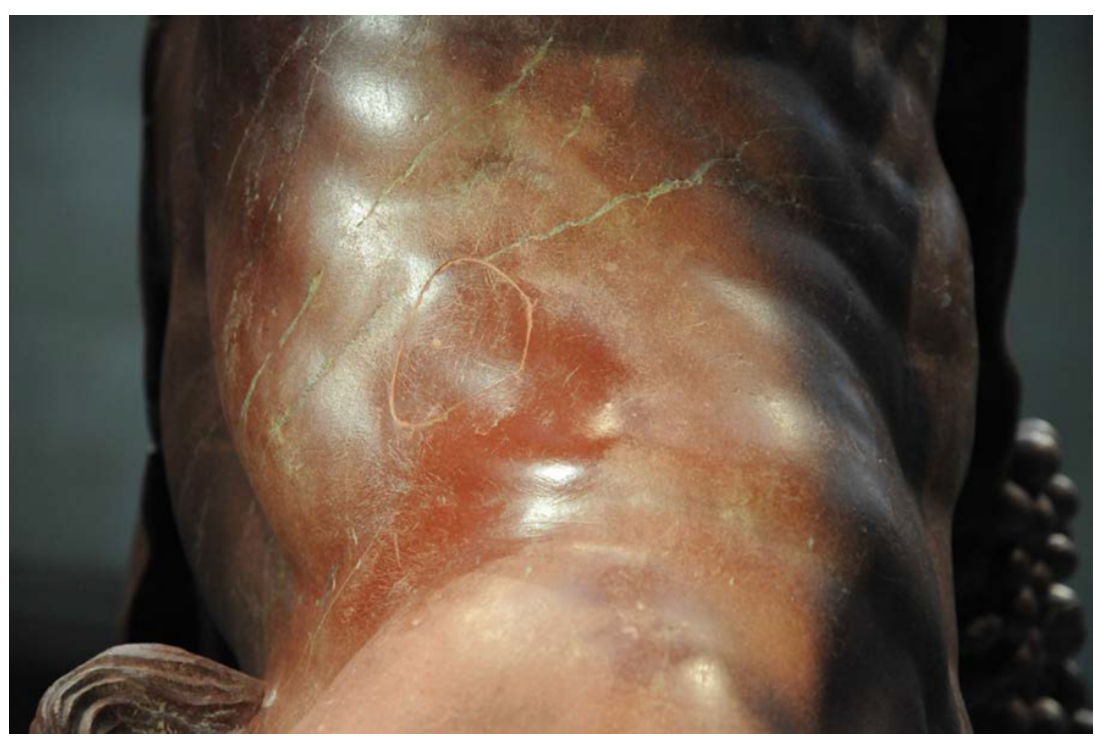

Figure 18. T-1: Restored surface area at right oblique.

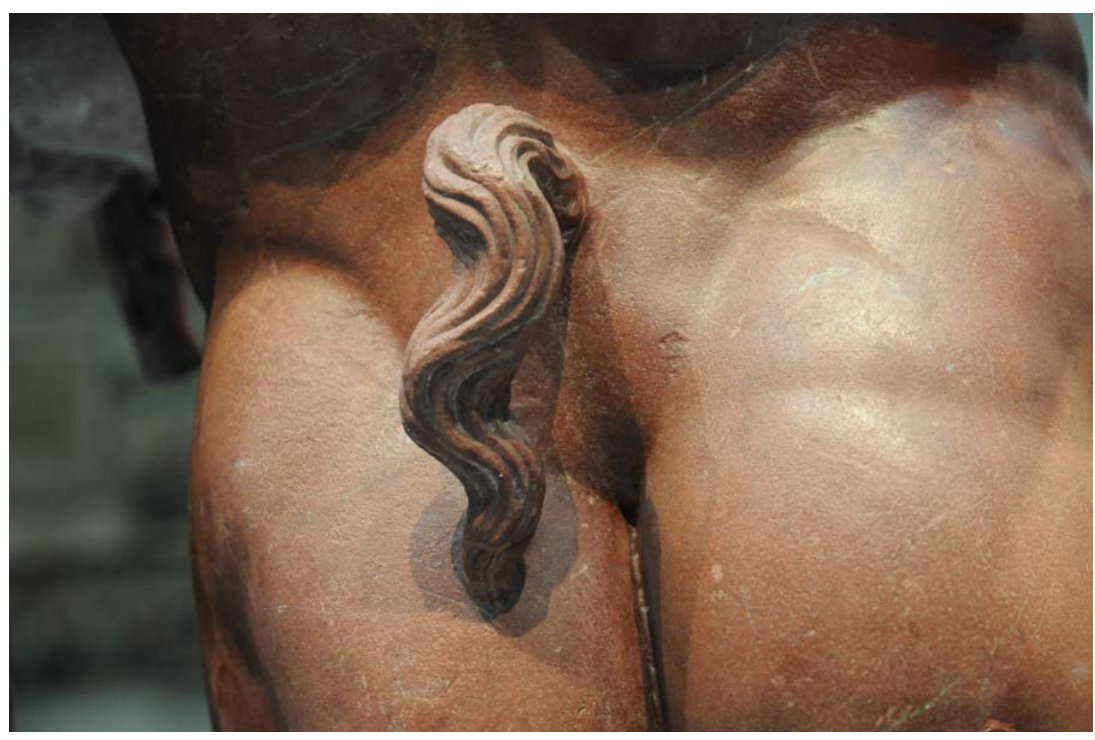

Figure 19. T-2: Evidence of a break at the base of the tail. It cannot be determined whether or not the hair is antique or modern since the textured surface obscures the appearance of the marble. T-3: The lower portion of the tail is joined to the upper tail with matte fill. As with T-2, the texture renders an assessment of originality indeterminable. T-4: End of tail joined to body with matte fill. As with T-2 and T-3, the texture renders an assessment of originality indeterminable. 
1:142 A. M. Ratigan

Right Leg: Restored.

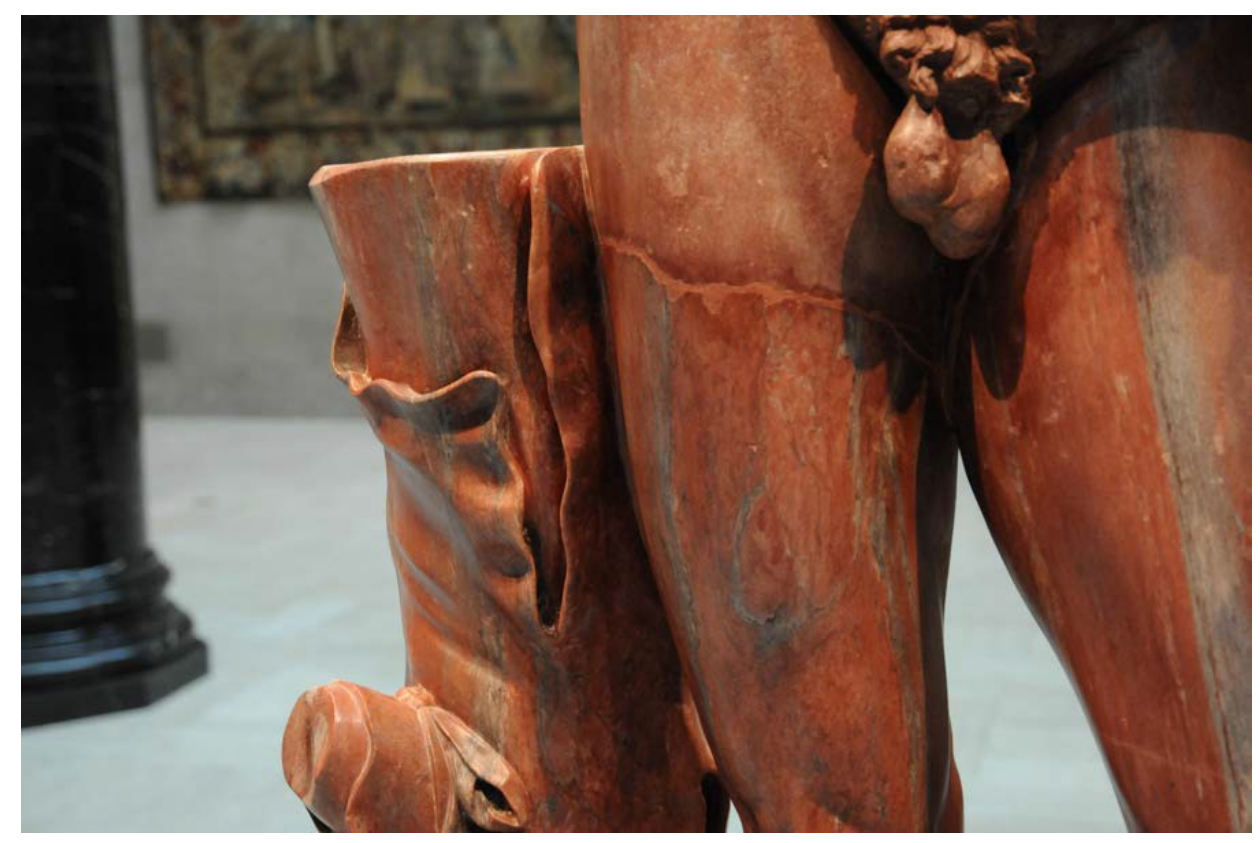

Figure 20. RL-1: Entire leg from upper thigh/lower buttock to ankle restored.

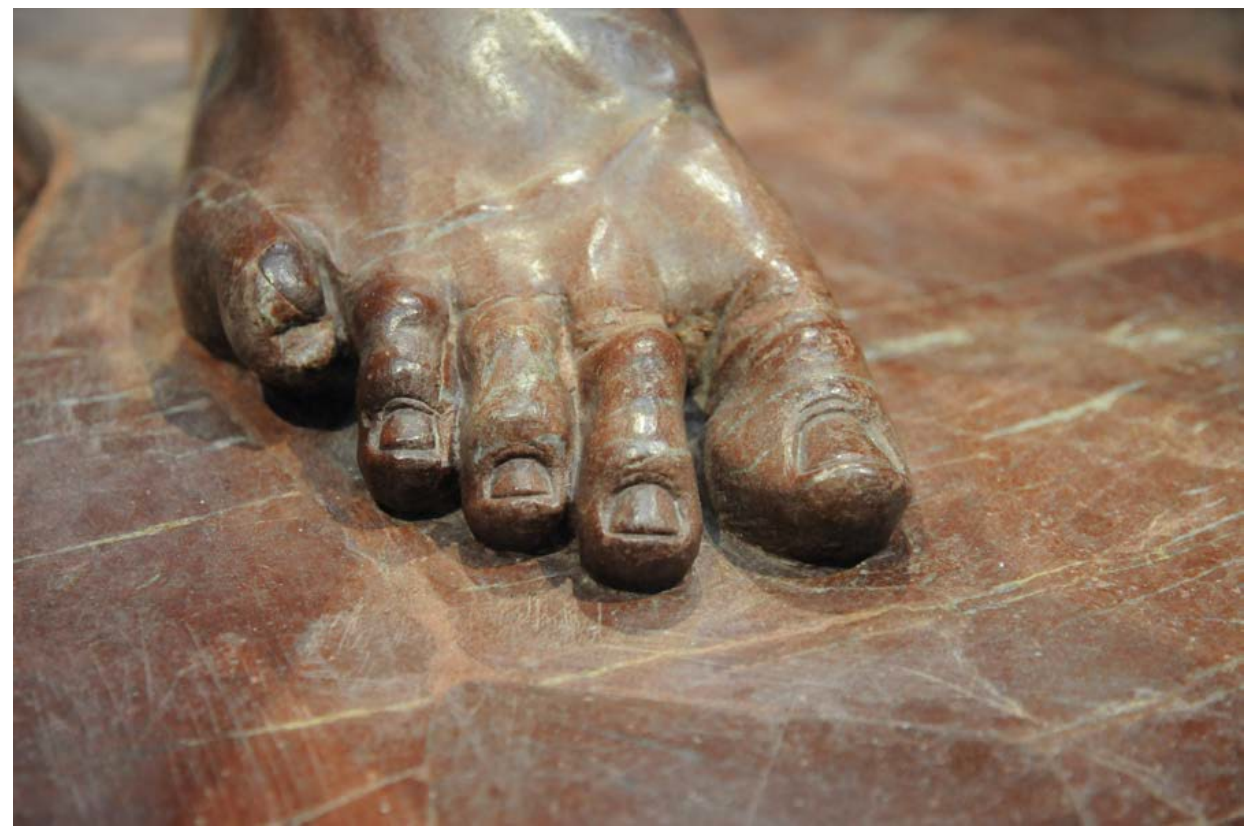

Figure 21. RL-2: At least four visible joins within the toes of the right foot. It cannot be determined if they are antique, but they closely match the appearance of the rest of the restored foot. 
Left Leg: Restored.

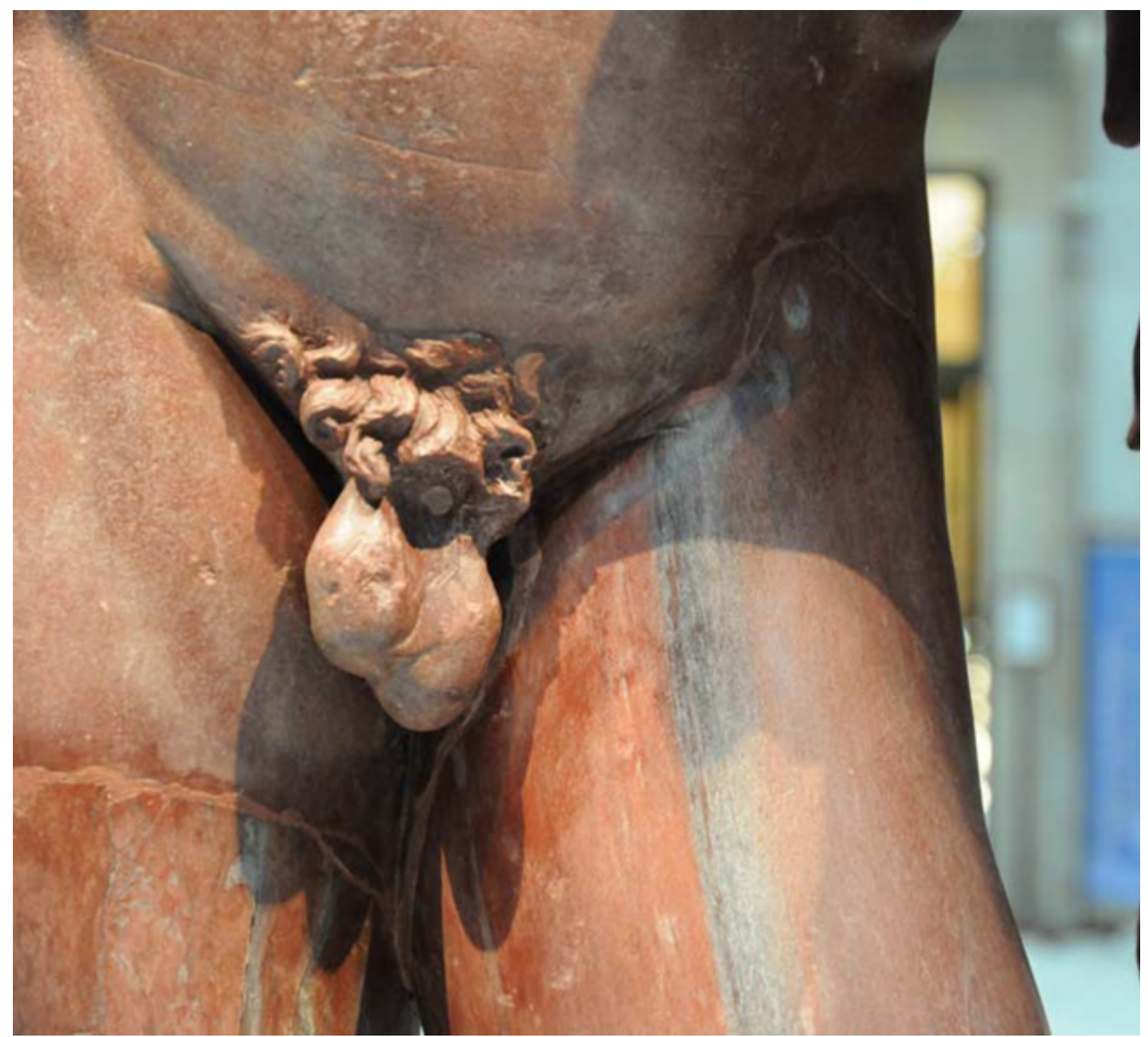

Figure. 22. LL-7: Upper leg is joined to the torso at the iliac crest/underside of the buttock. 
1:144 A. M. Ratigan

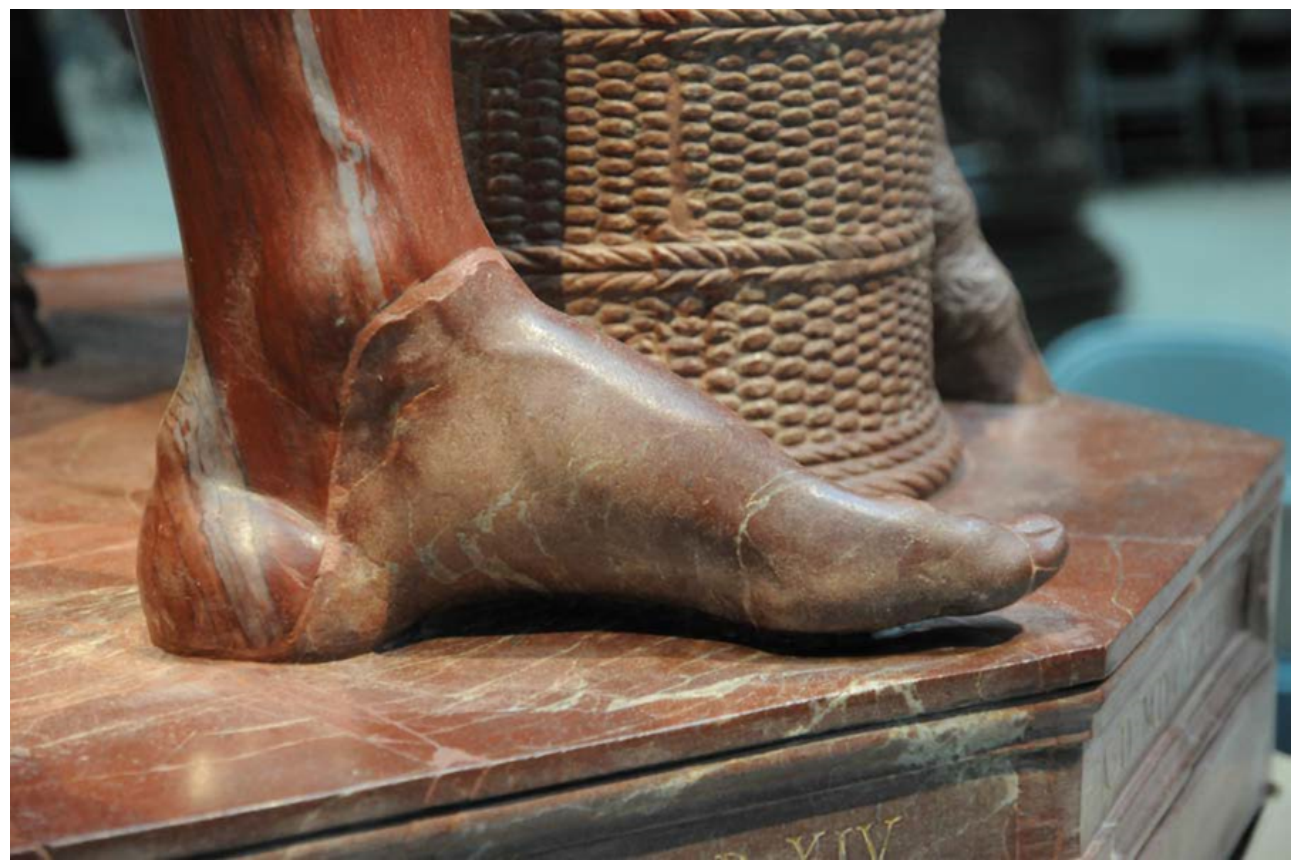

Figure. 23. LL-2: Leg to the heel is restored, antique top of the foot to the toes.

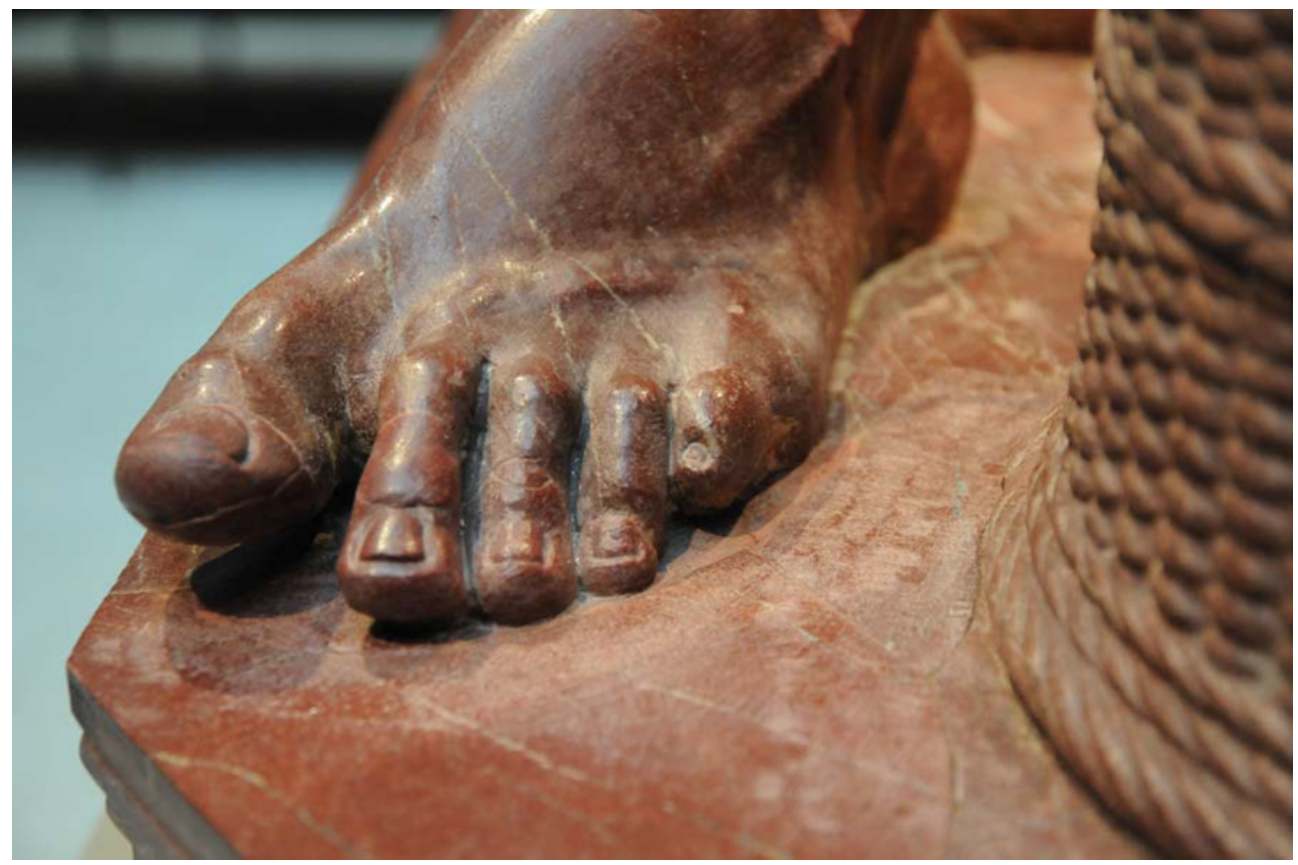

Figure 24. LL-3: Tips of the second, third, and fourth toes are restored. 
Nebris: Mostly ancient.

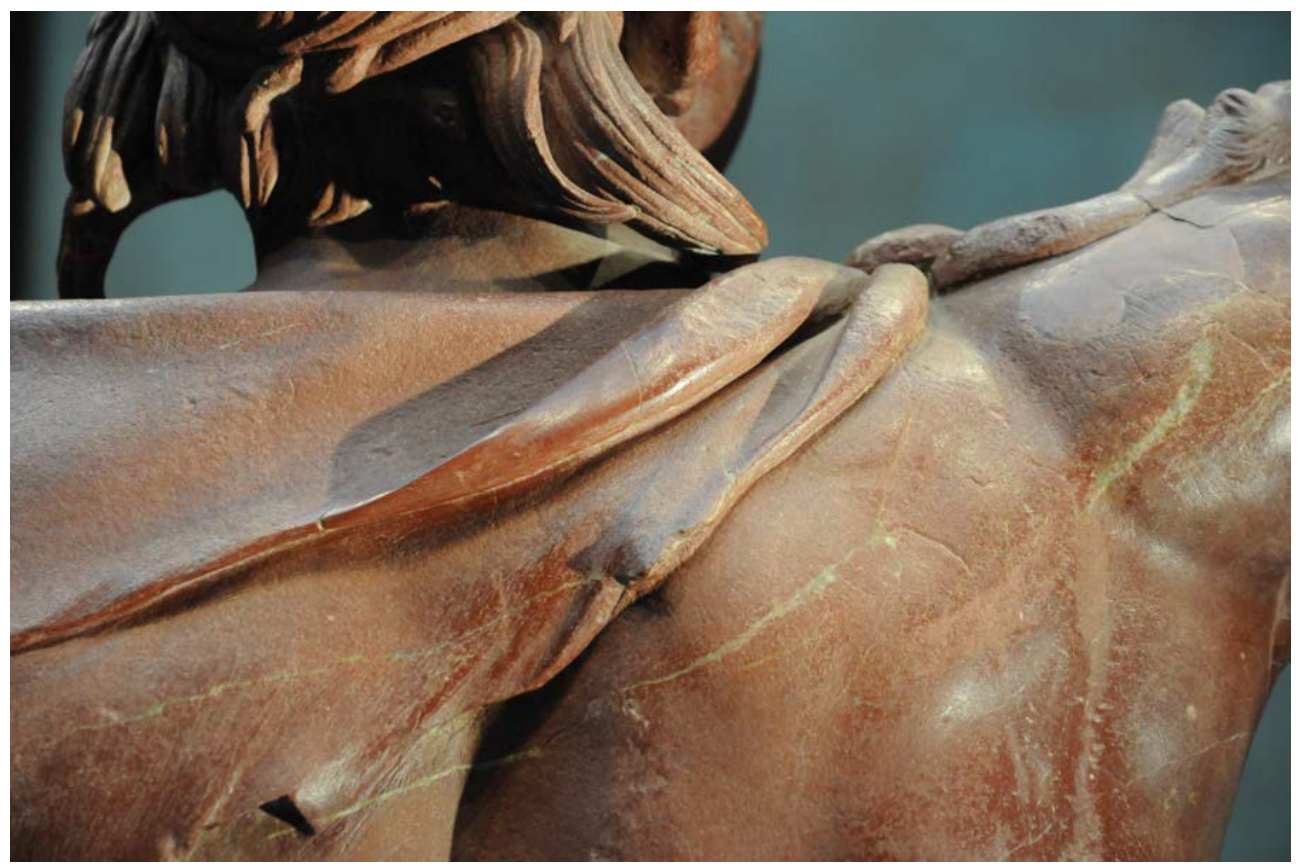

Figure 25. N-1: In the back, the upturned fold of the nebris at the right shoulder is restored.

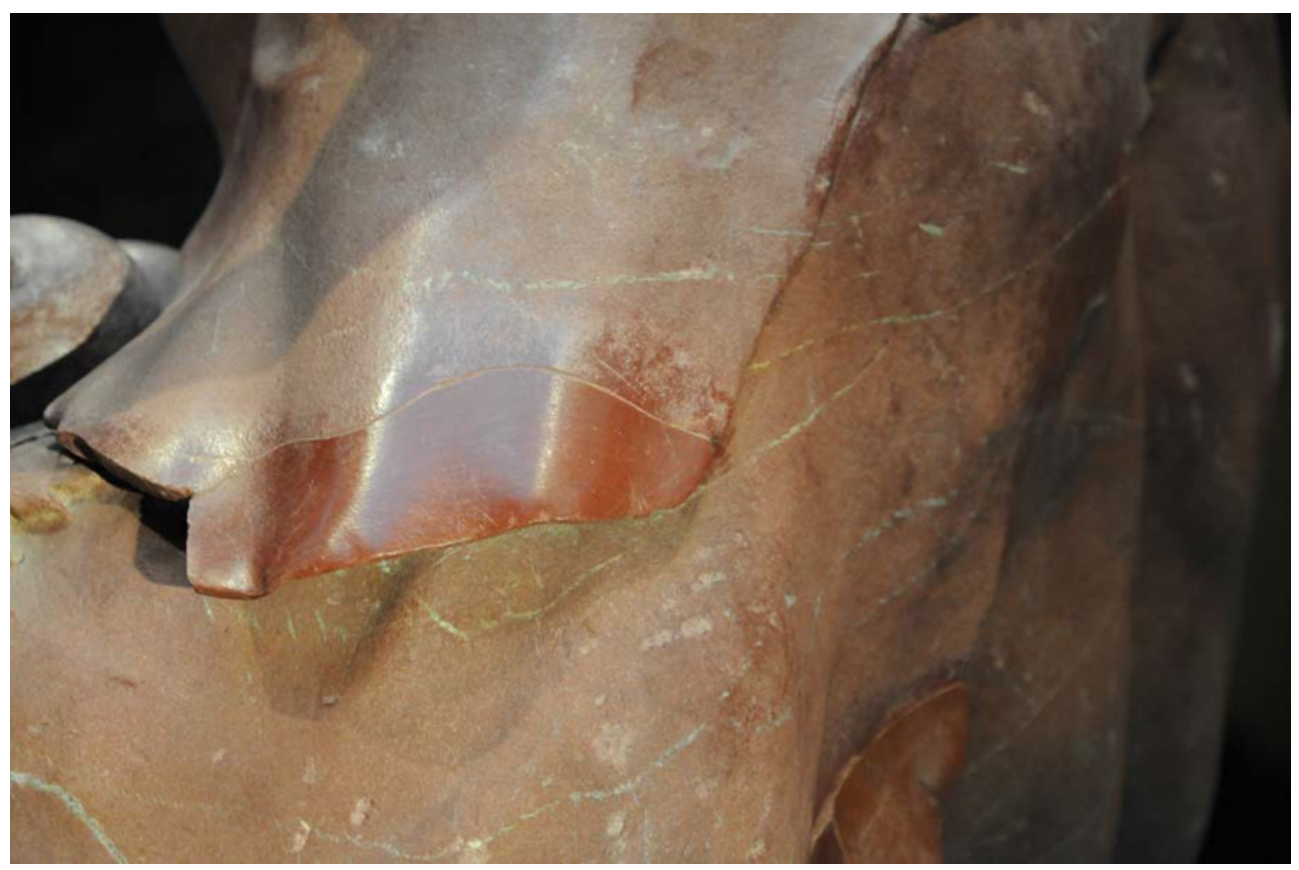

Figure 26. N-2: One of the edges of the nebris on the left arm is restored. 


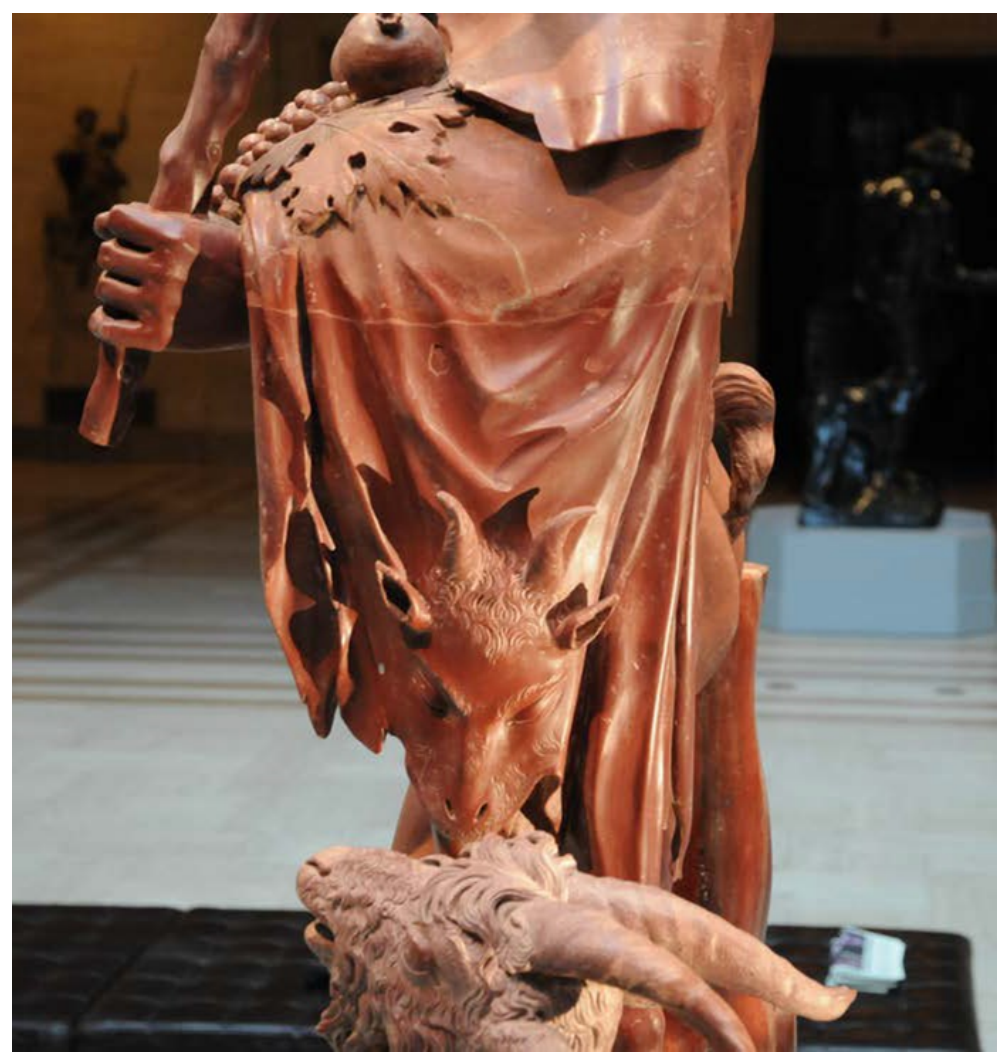

Figure 27. N-3: The nebris hanging below the left forearm, including its sculptured goat head, is restored.

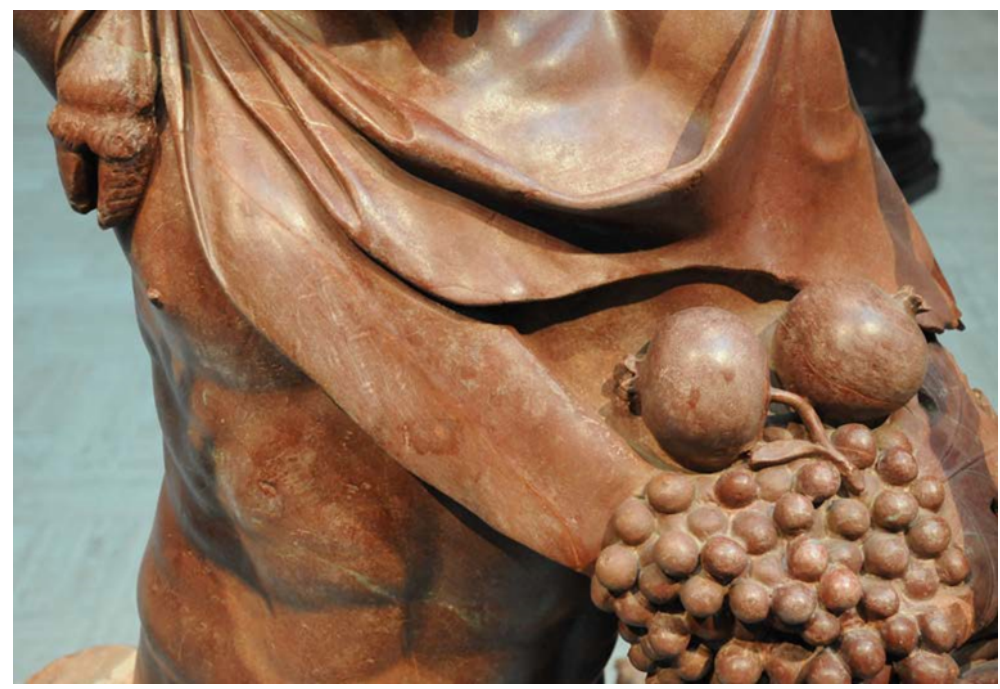

Figure 28. N-4: The lowest edge of the nebris hanging from the right pectoral to the fruit is restored. 
Fruit on the Nebris: Many grapes within the bunch restored.

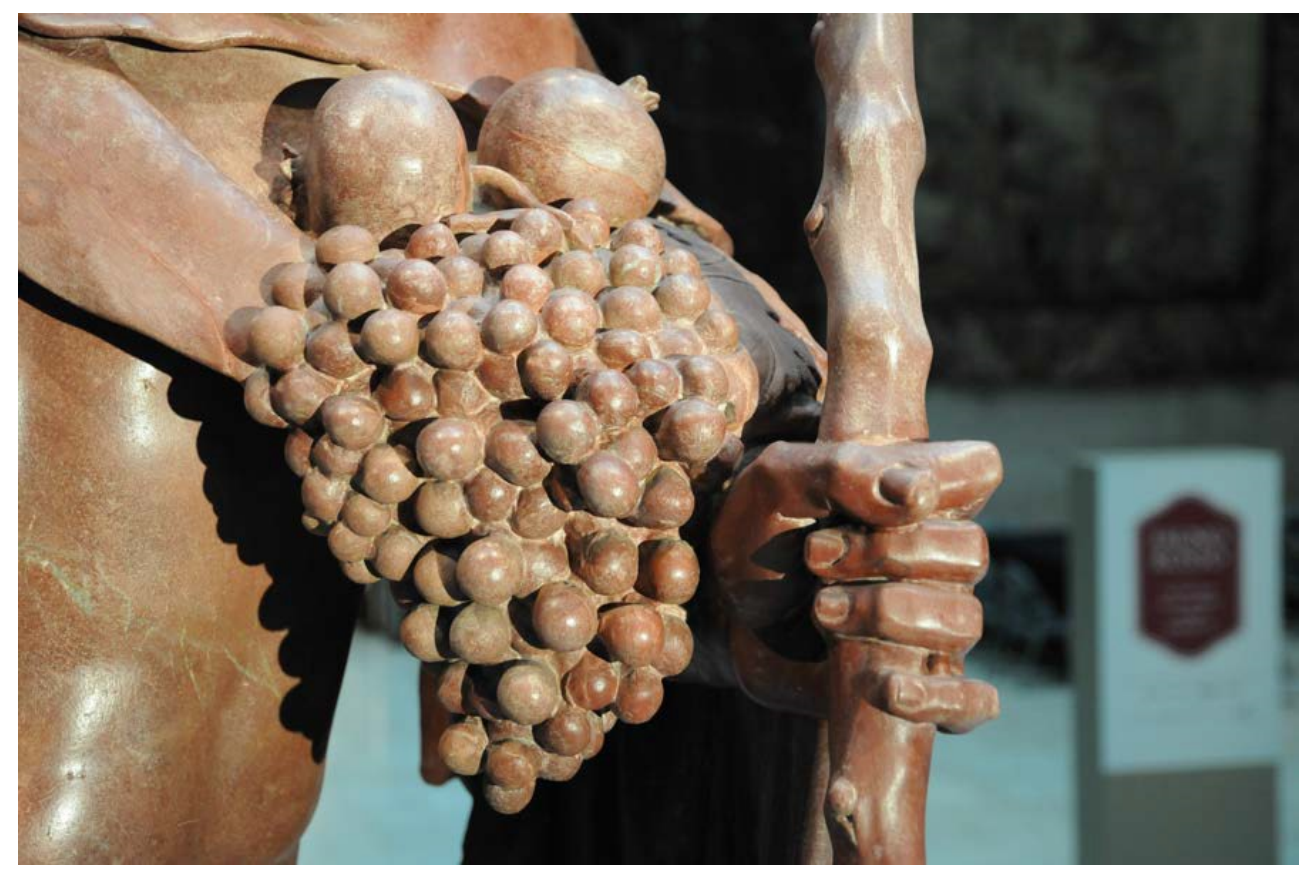

Figure 29. Detail, grapes and pomegranate.

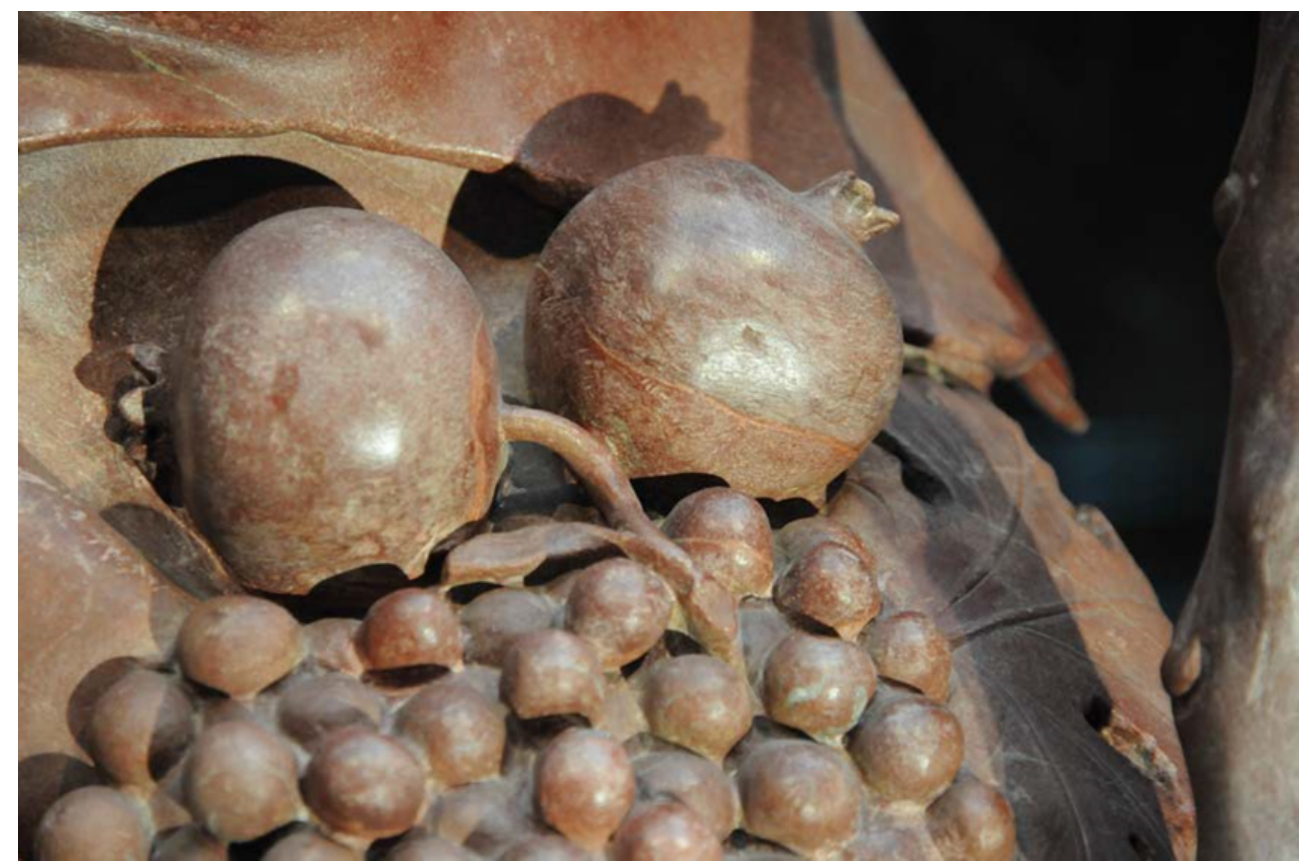

Figure 30. FN-1: antique top halves of pomegranate, lower half and stem restored. 
Goat. There are many visible breaks and joins. The texture makes the task of appraisal problematic, but it is clear that the goat was not found intact. Capponi did not mention a goat at all in his accounts-neither in a fragmentary state nor as part of the finished product. Some of the goat appears quite similar to those undisputed, genuine fragments of the Faun.

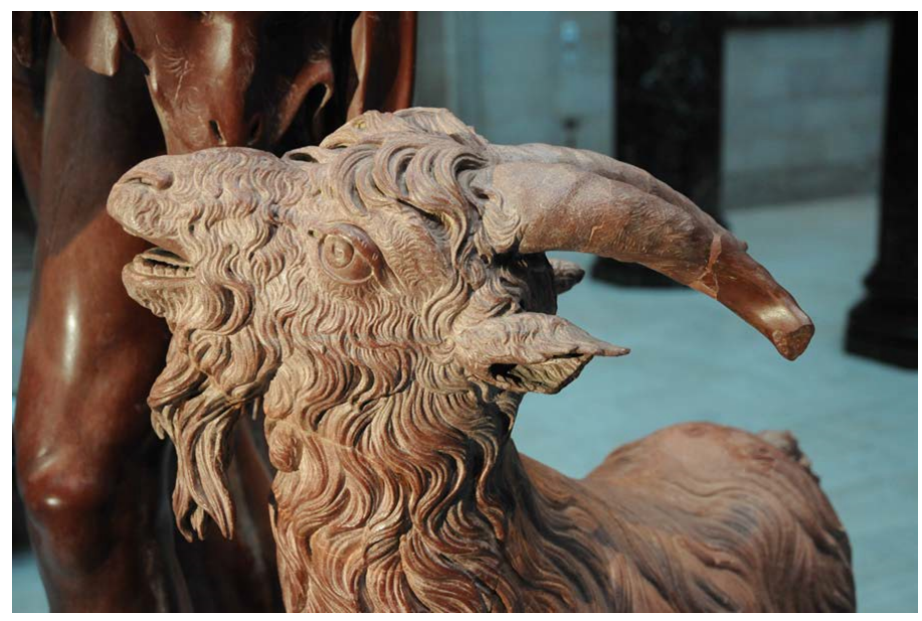

Figure 31. G-1: Restored tip of left horn, surface is smoother than the textured lower horn. G-2: Join separating head and neck; the fur of the head is of a lighter color. See Figure 32.

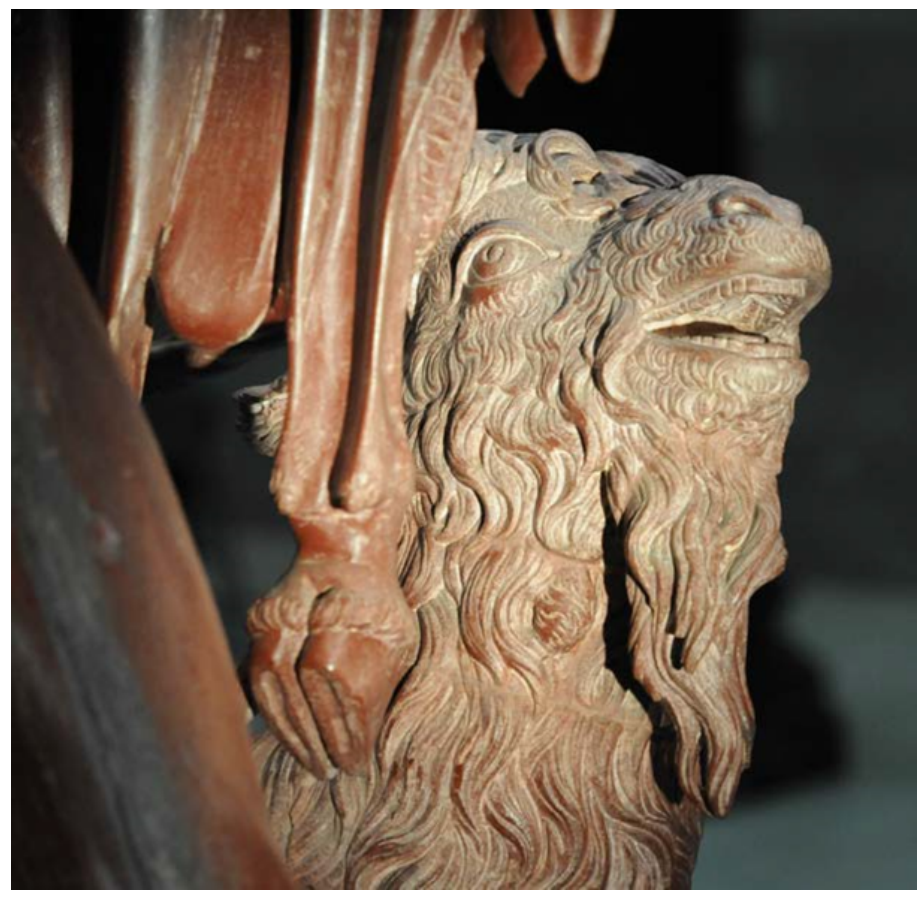

Figure 32. G-3: Join just below G-2, creates cross-section that includes the dewlaps and separates the head and the breast. 


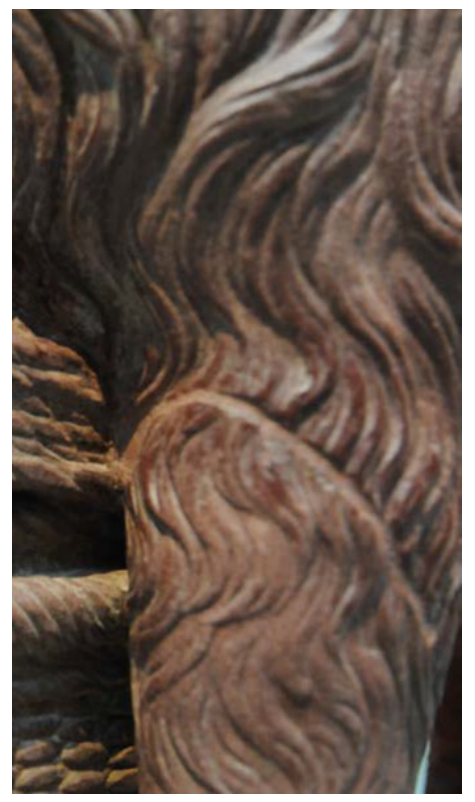

Figure 33. G-4: Join separates the left foreleg from the body.

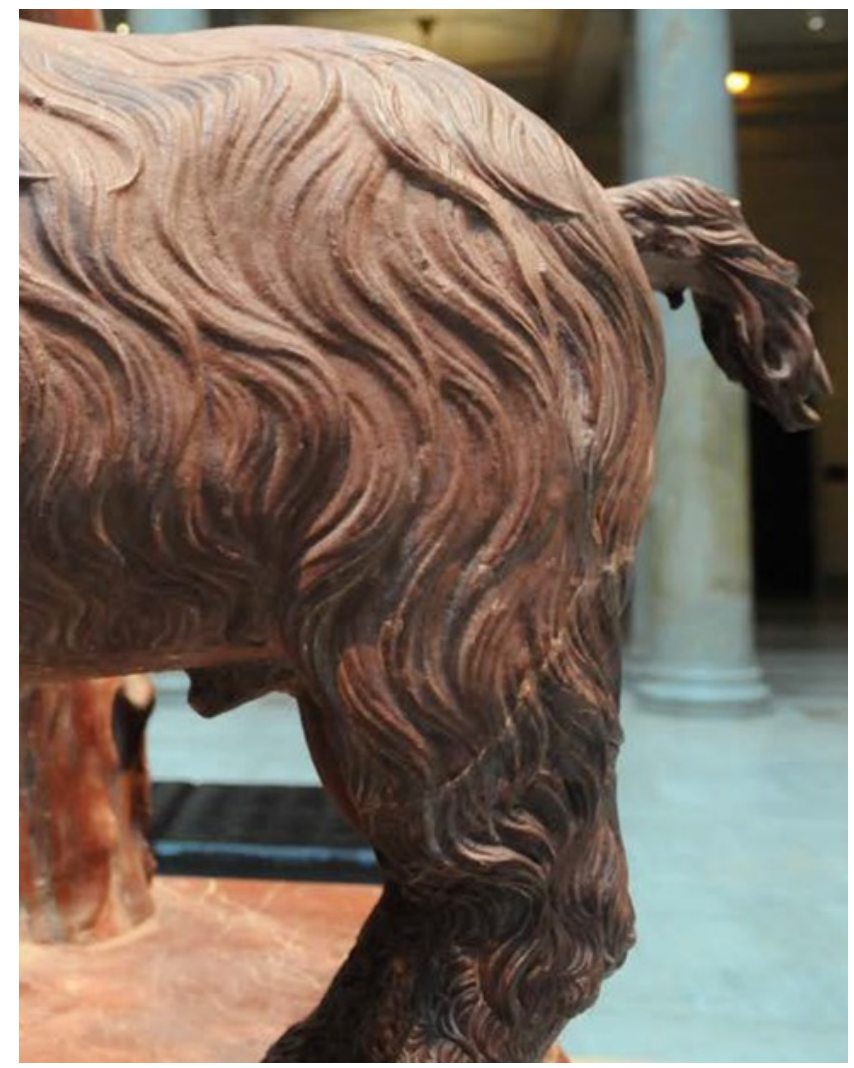

Figure 34. G-5: Join at the top of the rear left leg. 


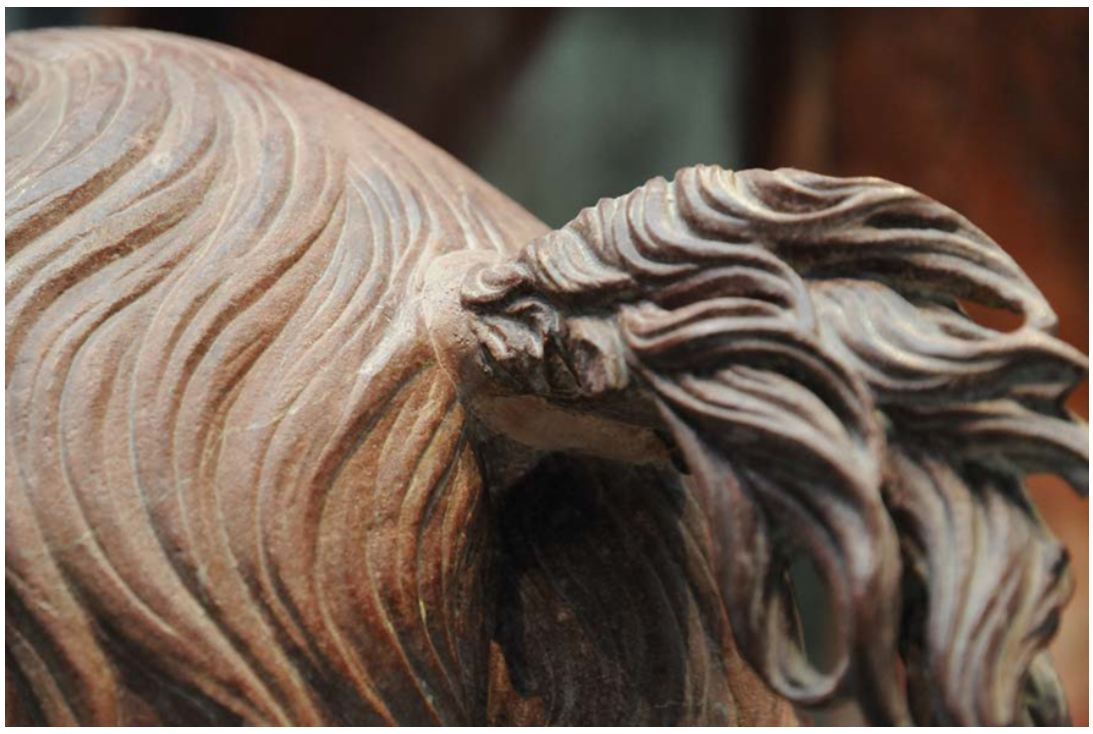

Figure 35. G-6: Tail is joined to the body with matte fill.

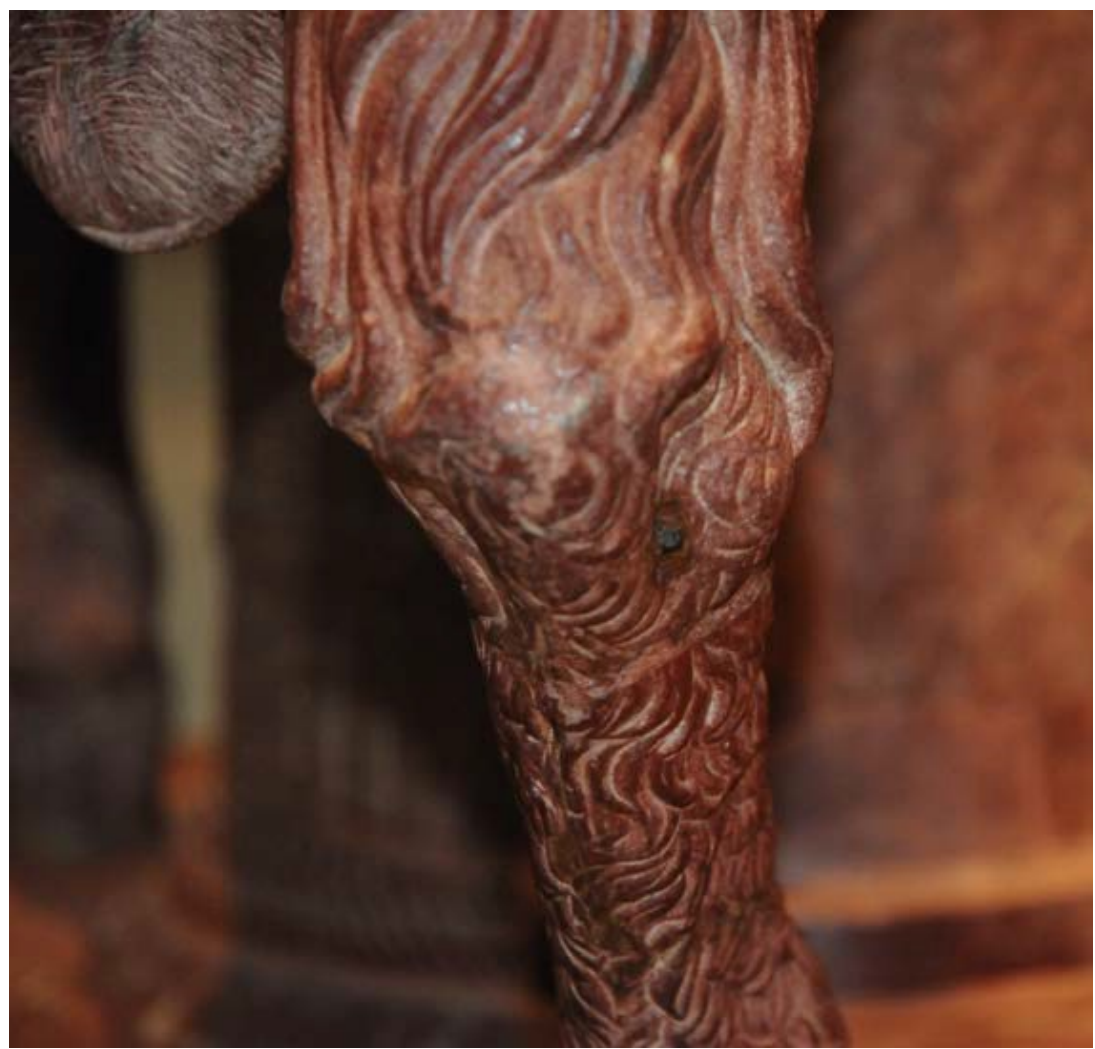

Figure 36. G-7: Lower portion of rear right leg features a pin above the break and below the thigh. 


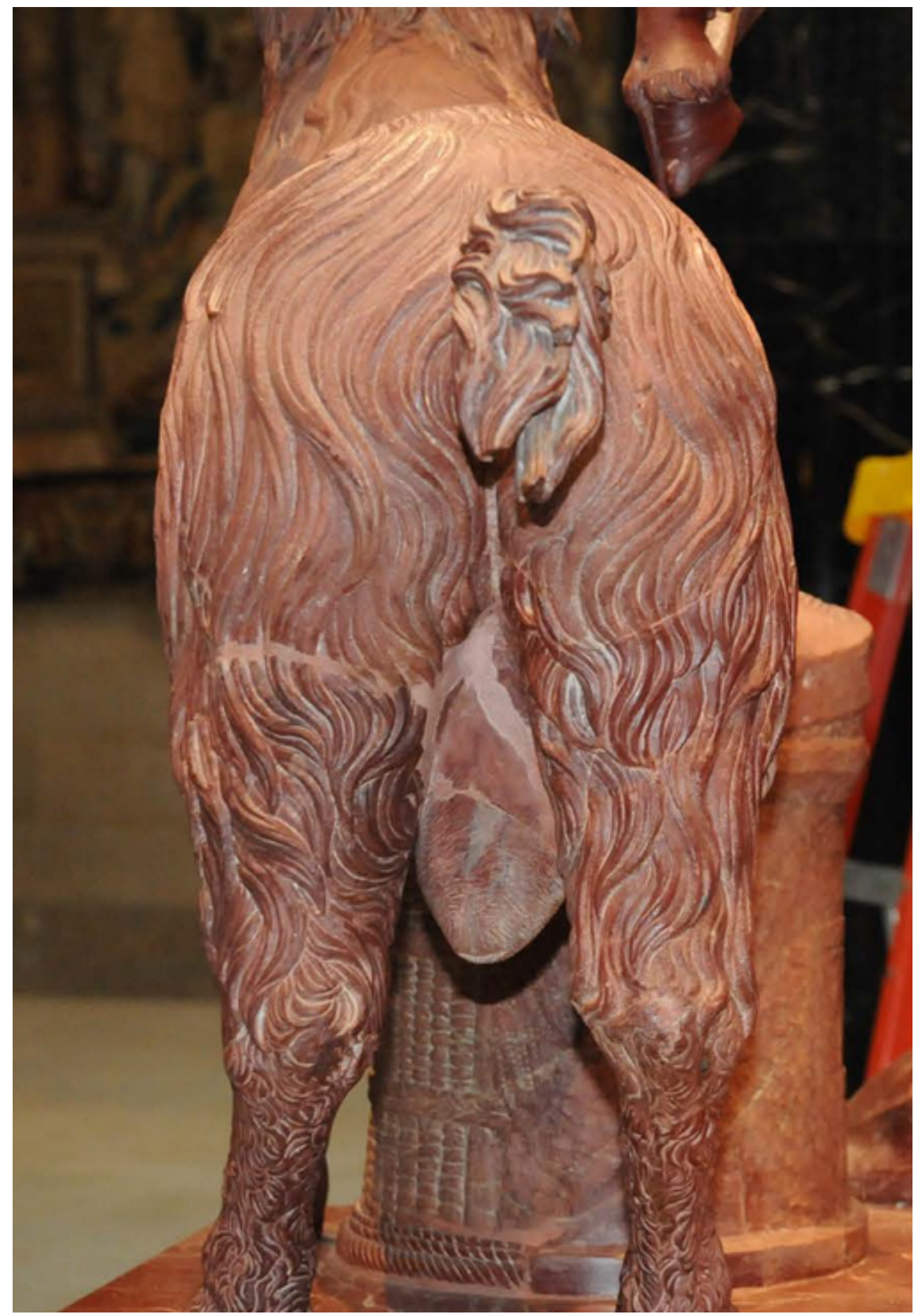

Figure 37. G-8: The genitals of the goat are composed of many fragments and matte fill. 


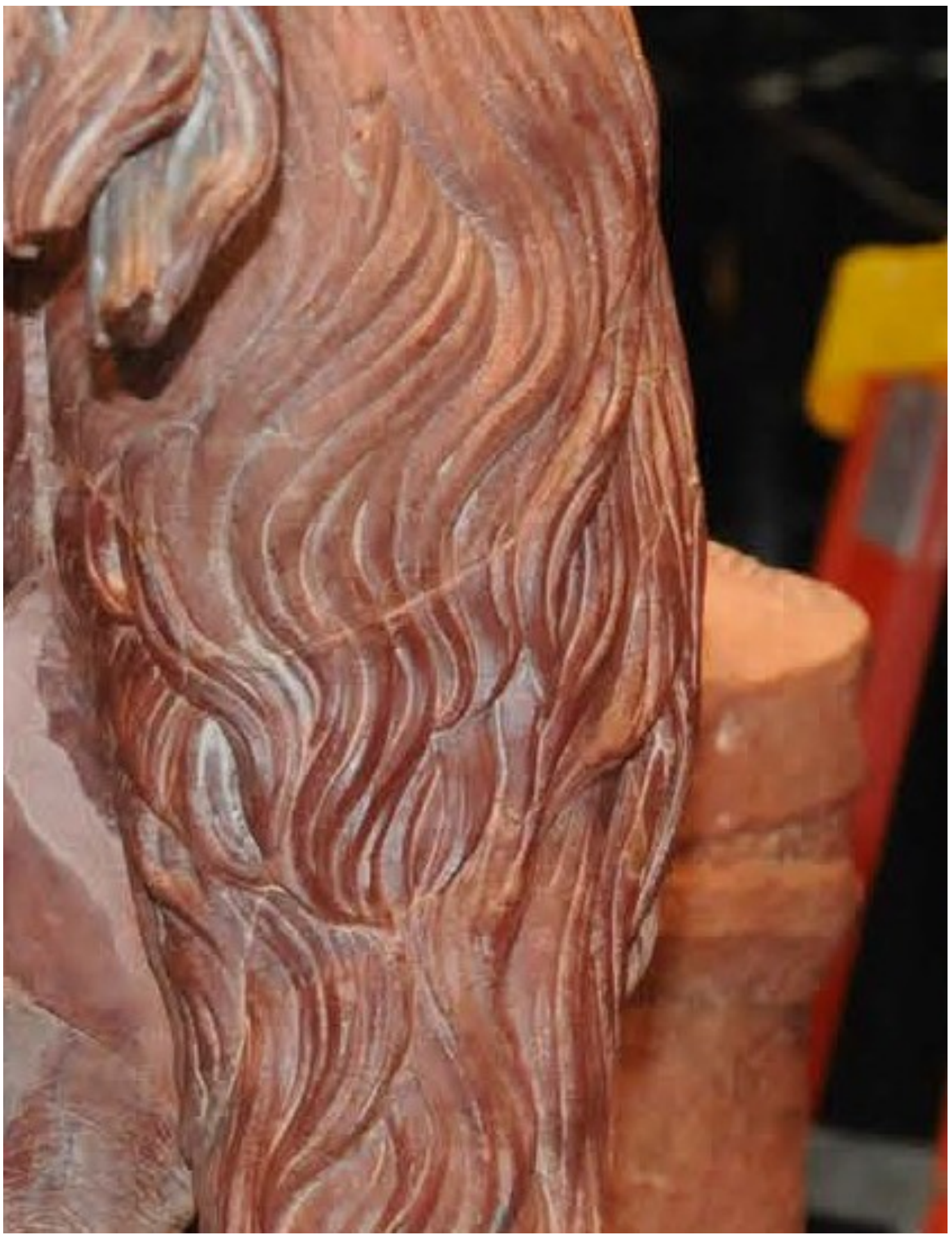

Figure 38. G-9: Join between upper right backside and top of the leg by a surface fragment of fur. 
Basket. The basket is composed of many joined fragments. The textured surface makes the task of determining which portions are antique and which are restorations difficult. The following is an enumeration of joins.

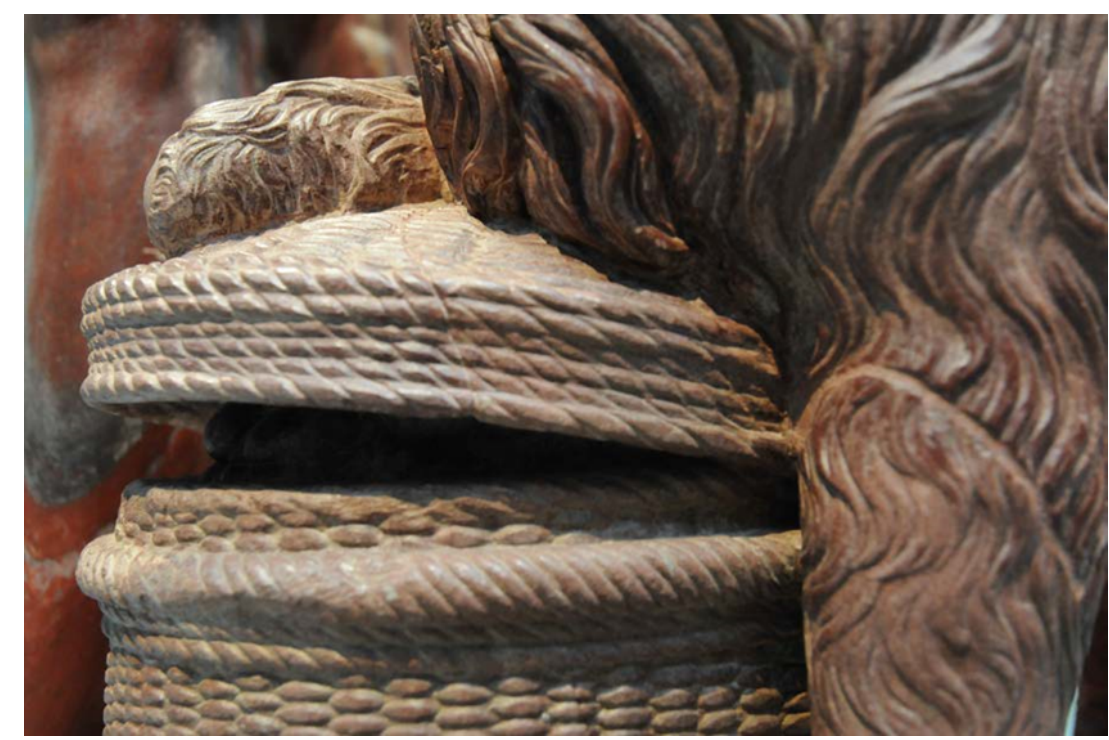

Figure 39. B-1: Break from top of the lid near the goat's knee to lip of the lid.

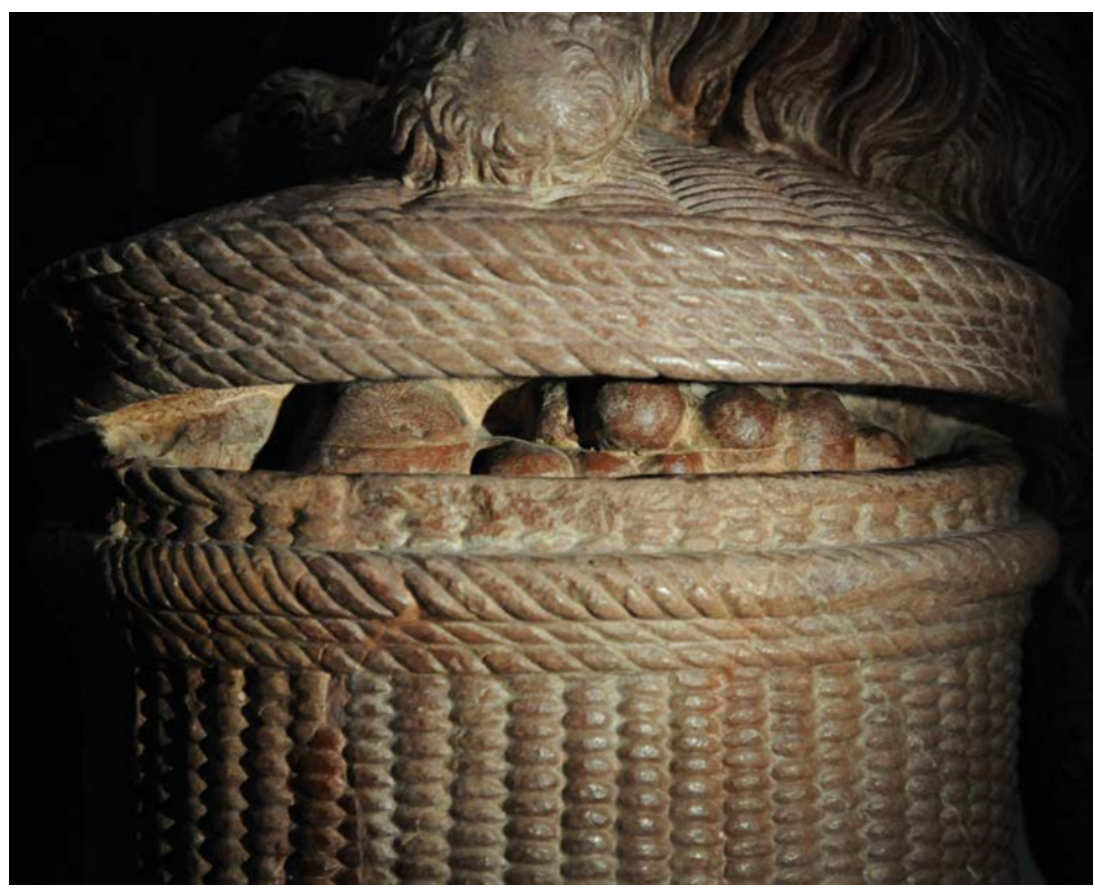

Figure 40. B-2: Single join extending through the middle of each of the fruits. 
1:154 A. M. Ratigan

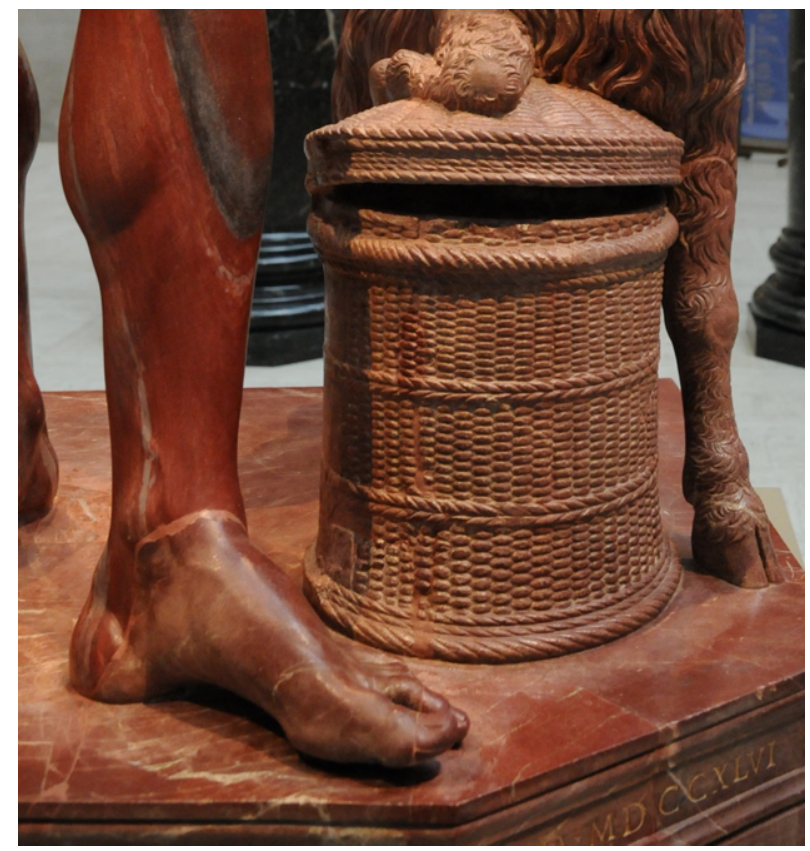

Figure 41. B-3: Vertical break along the height of basket's right side.

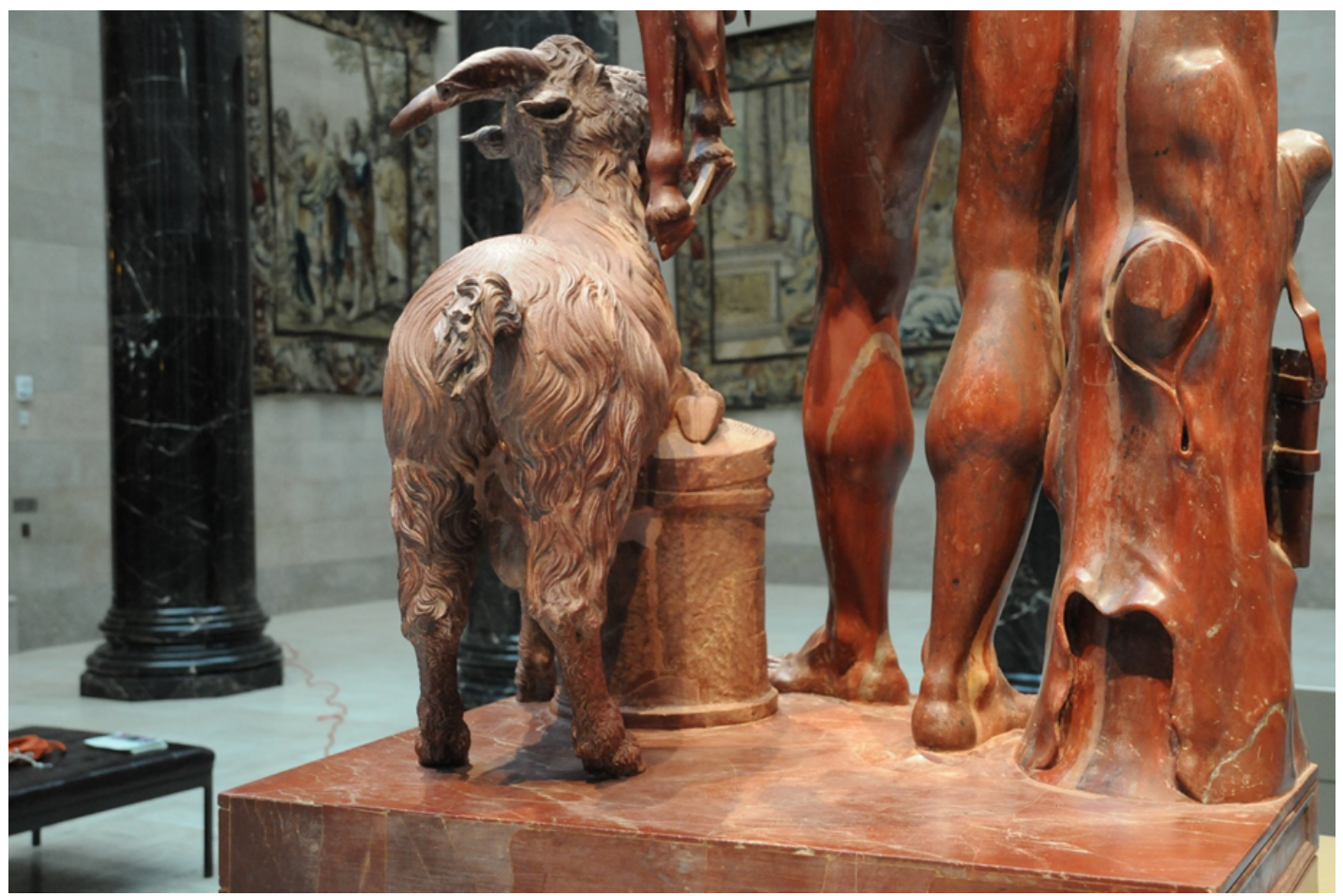

Figure 42. Incidental photographs of the rear of the goat suggest that the basket was heavily restored on its rear right side; this restoration does not feature the basket texture. 
Support. Mostly restored.

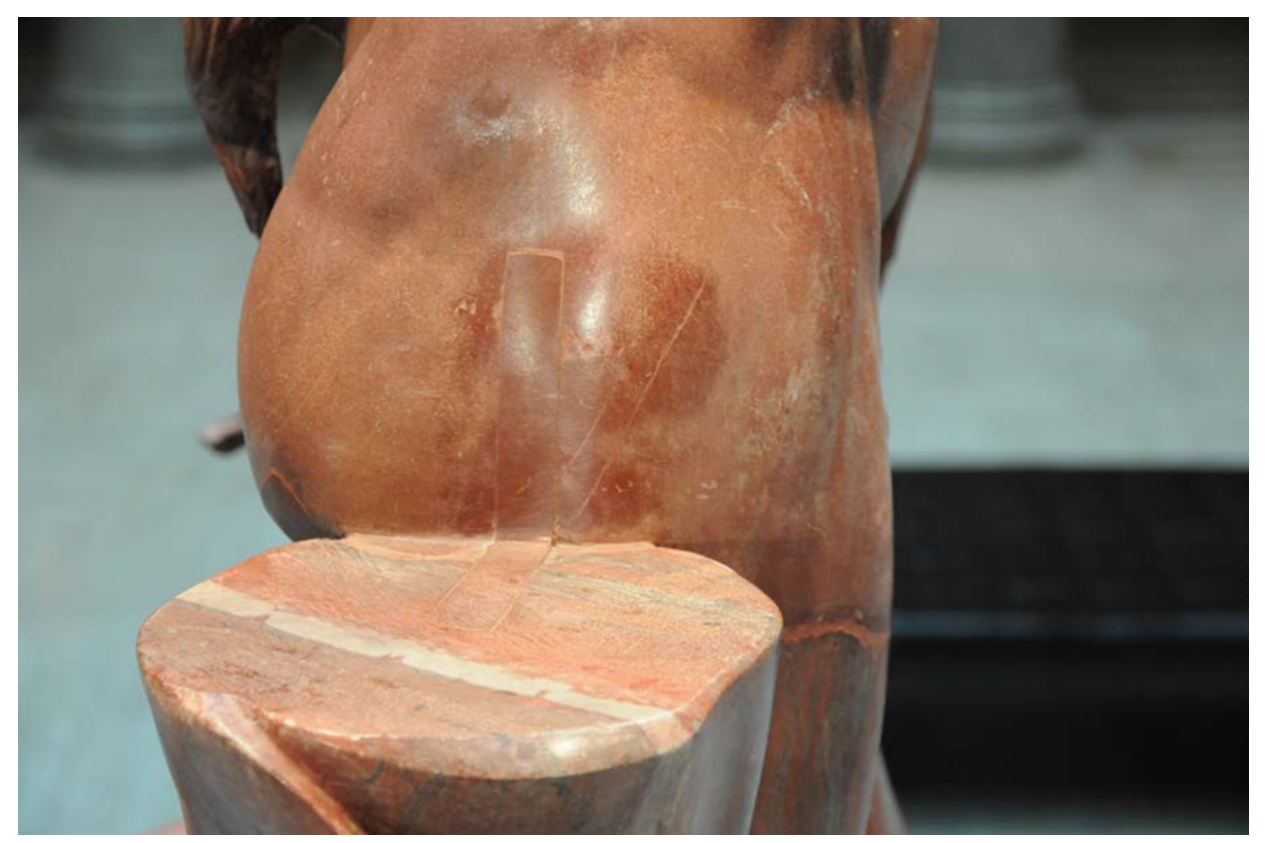

Figure 43. The support is attached to the Red Faun's right hip with matte fill and also with the insertion of a rectangular wedge into the hip to secure it in place.

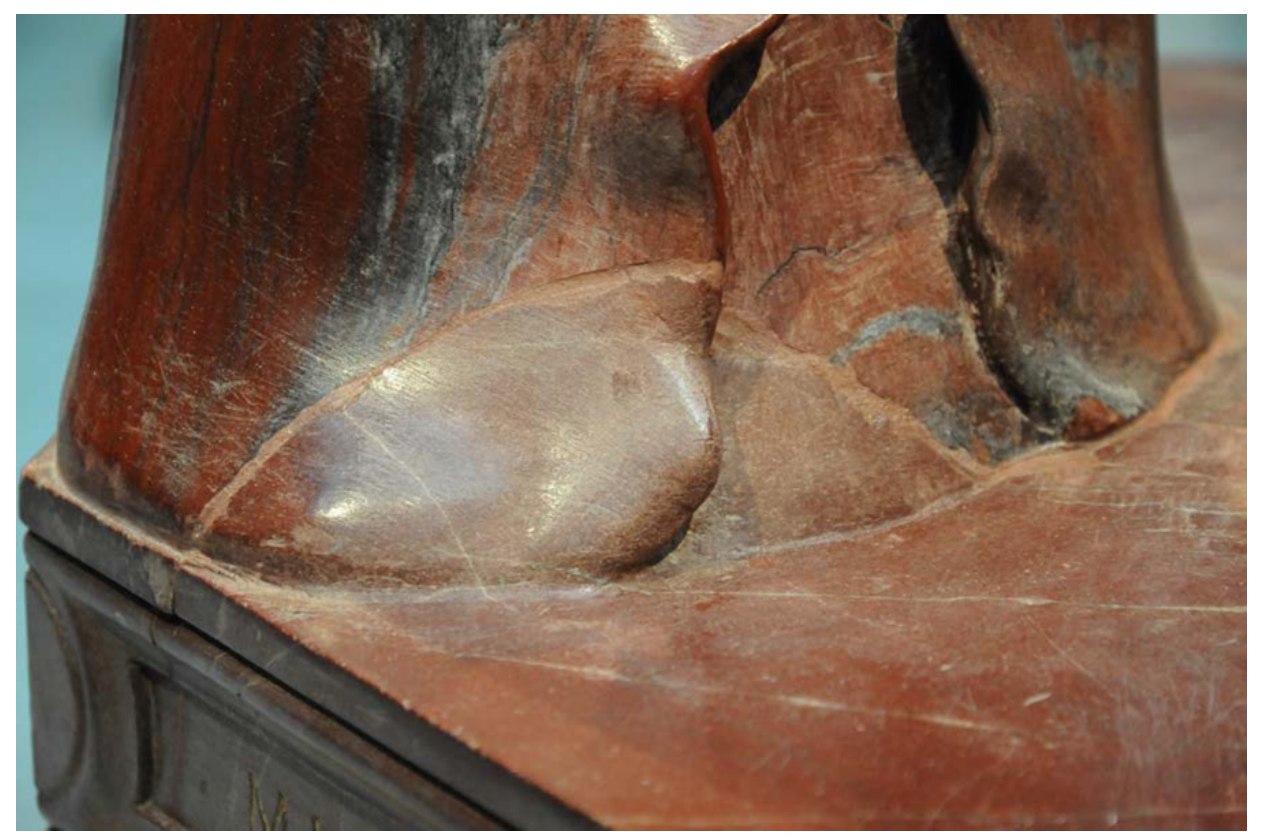

Figure 44. S-1: Join between the antique part at the base connecting the front of the support to the plinth. 
Plinth: The catalogue entries of Barberini, Helbig, Jones, and Raeder all agree that some considerable portion of the base is restored. Capponi's role and observations, bound up in Barberini's description, are privileged, as he was a witness to the statue before, during, and after its restoration. He reported that Pope Benedict sent him half of the base along with other pieces-22 "tiles" of rosso antico in total.

The following catalogue was developed with the assistance of Cohon's incidental photographs as well as the observations the present author was able to make in the Sala del Fauno in the Capitoline Museums in Rome. A window opposite the sculpture in the museum dramatically lights the Faun, obfuscating the surface treatment of the plinth toward the rear and inhibiting photographic clarity. Further inhibiting the distinction between antique and modern restoration is the surface treatment itself. Various fragments of both types are abraded or polished, and it seems that neither ancient nor modern elements were uniformly handled. Nevertheless, this is an attempt to identify the antique fragments by differentiating the genuine white veins from the grey veining of the restoration marble.

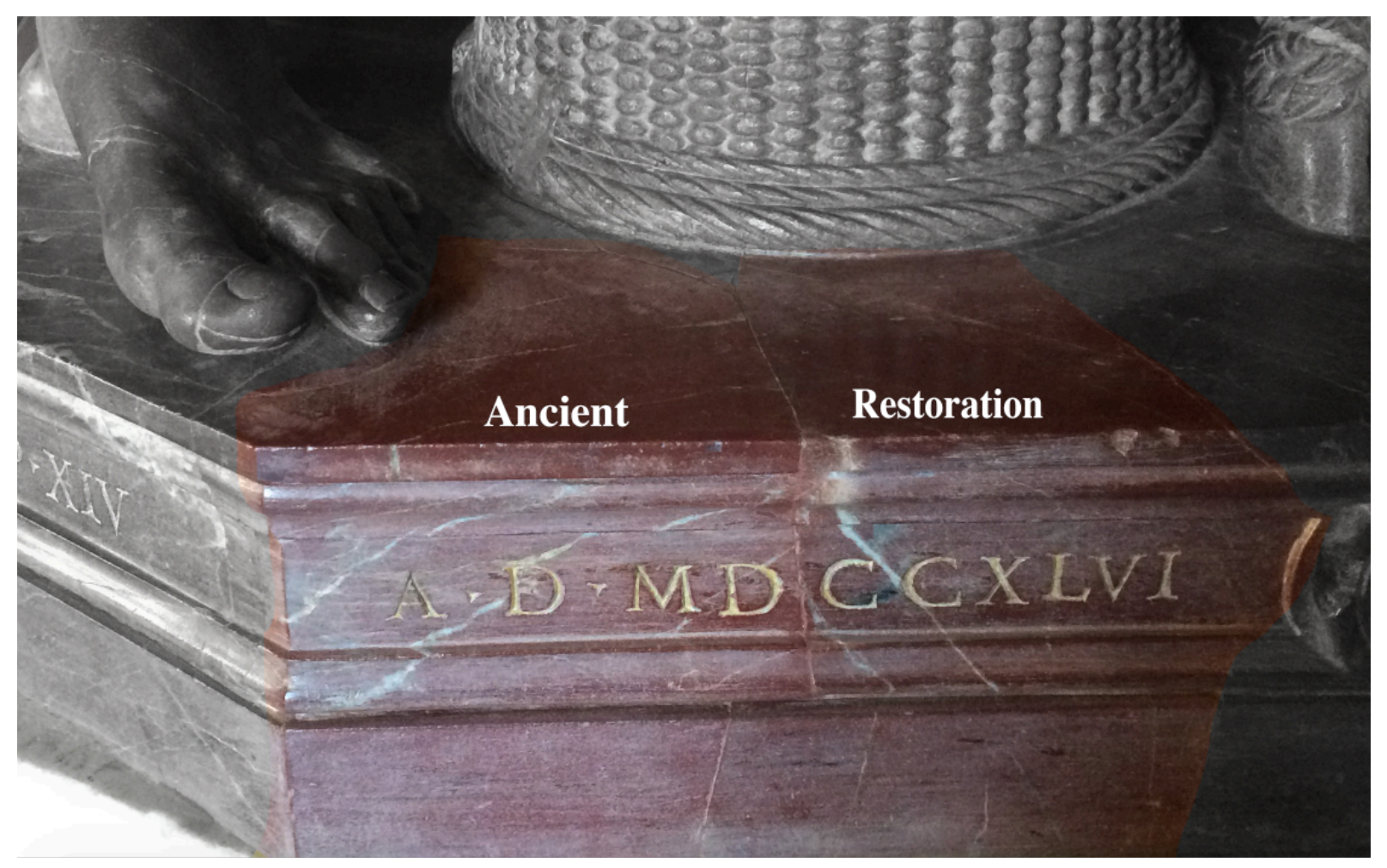

Figure 45. P-1: The front left (proper) panel, which reads "A D MDCCXLVI" features a seam between "MD" and "CC" that delineates the ancient $(P-1)$ and modern (note the grey veins running through the marble of restoration). 


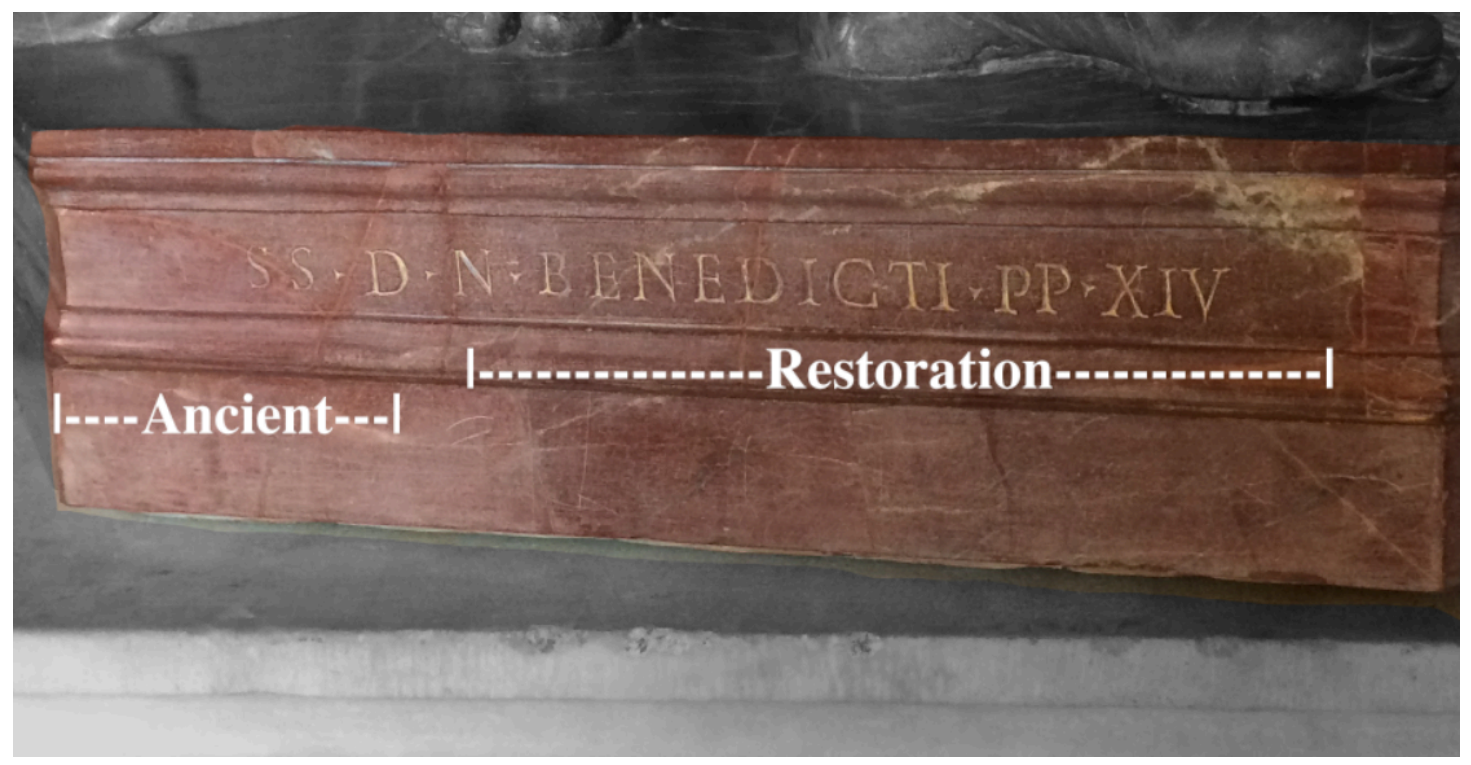

Figure 46. P-2: The center front panel, reading "SS D N BENEDICTI PP XIV" is composed of many pieces. Those to the left of "SS D" are ancient (P-2) and those to the right are restoration.

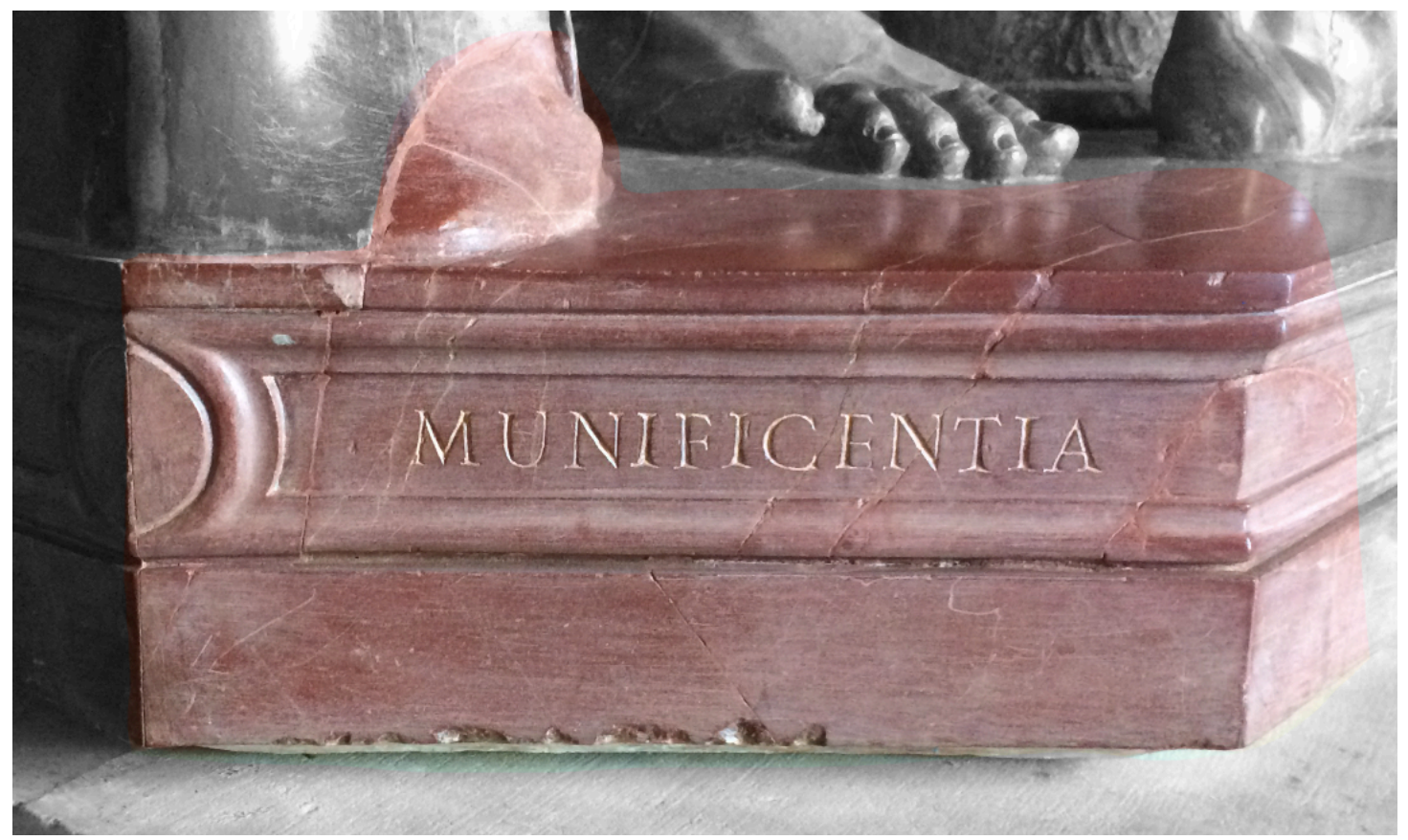

Figure 47. P-3: The front right (proper) panel is composed of many pieces, none of which reveal grey veins. The pieces are differentially abraded, but the corner fragments have two faces visible-one on this panel and the other part of the ground on which the Faun stands. This aids in distinguishing color. Certainly the tile that reads "MUNIFIC" is ancient, as it appears to join with the ancient lower part of the trunk. With caution, the author considers the various parts of this panel ancient. 


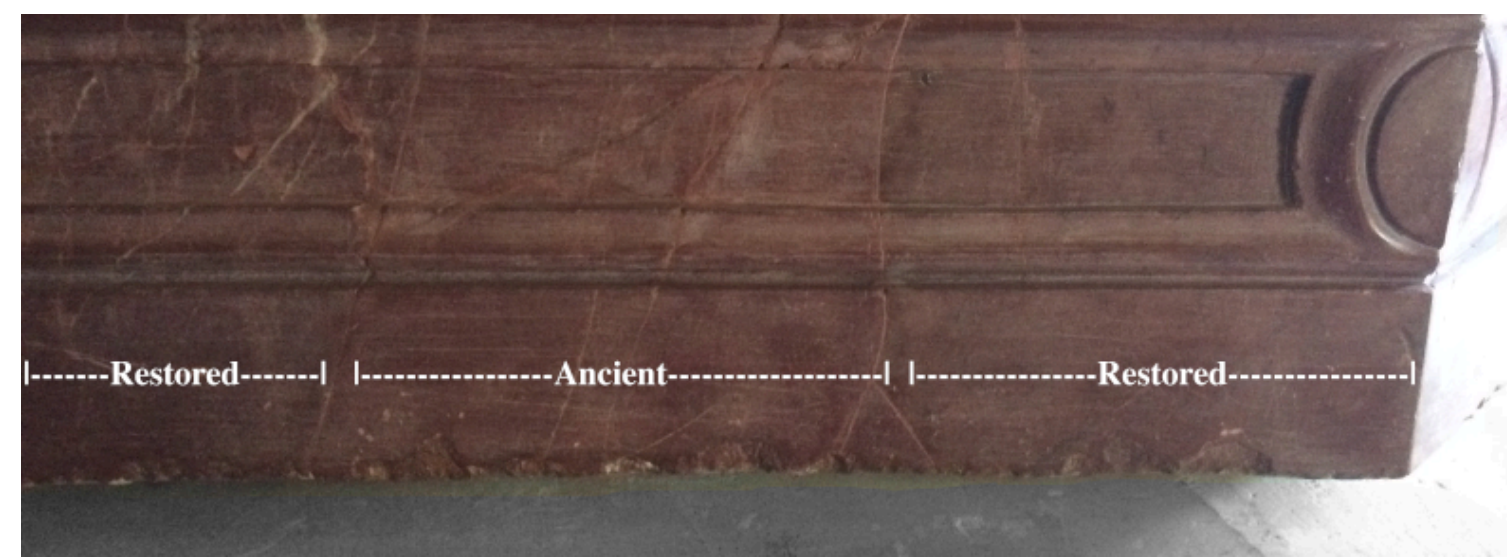

Figure 48. P-4: The right-side panel is separated from the panel seen in Fig. 48 (P-3, above) by a vertical join along that corner. Again, it is composed of many fragments. P-4, a collection of ancient fragments, can be seen marked in the center of the panel. This side panel is mostly restoration; more fragments of restoration continue to its back corner (not pictured).

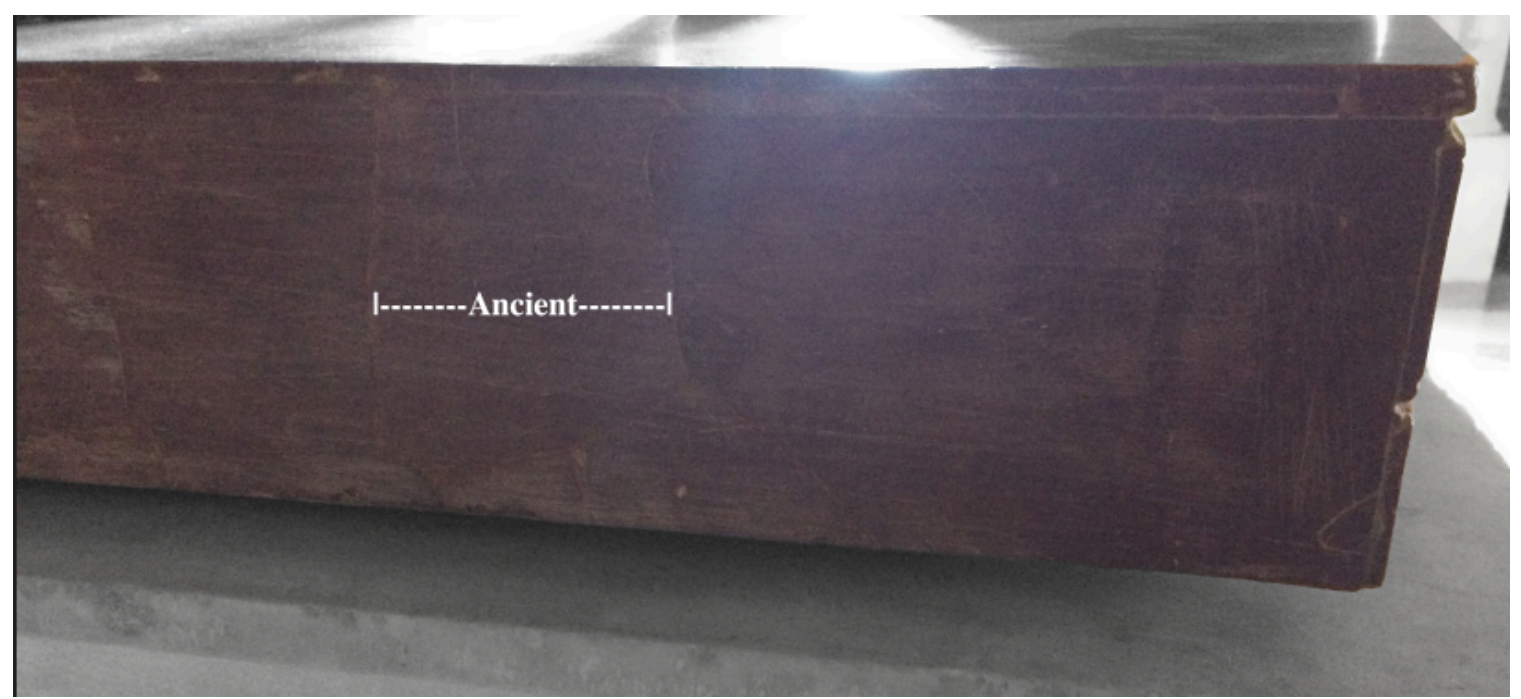

Figure 49. P-5: The rear panel is composed of many fragments, both restored and ancient. The first of the ancient fragments $(P-5)$ is pictured here.

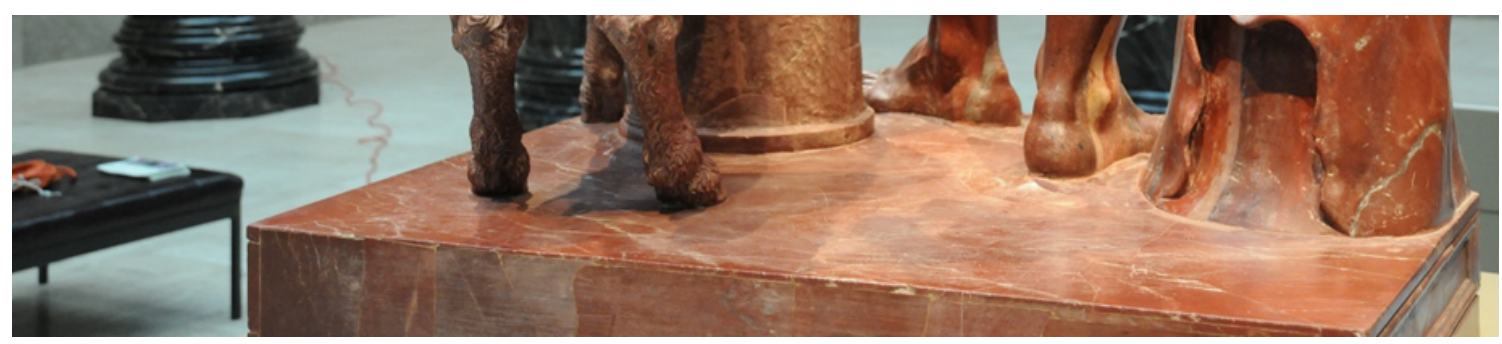

Figure 50. P-6 and P-7: Further to the left in the rear panel are another two ancient non-joining fragments (P-6). 


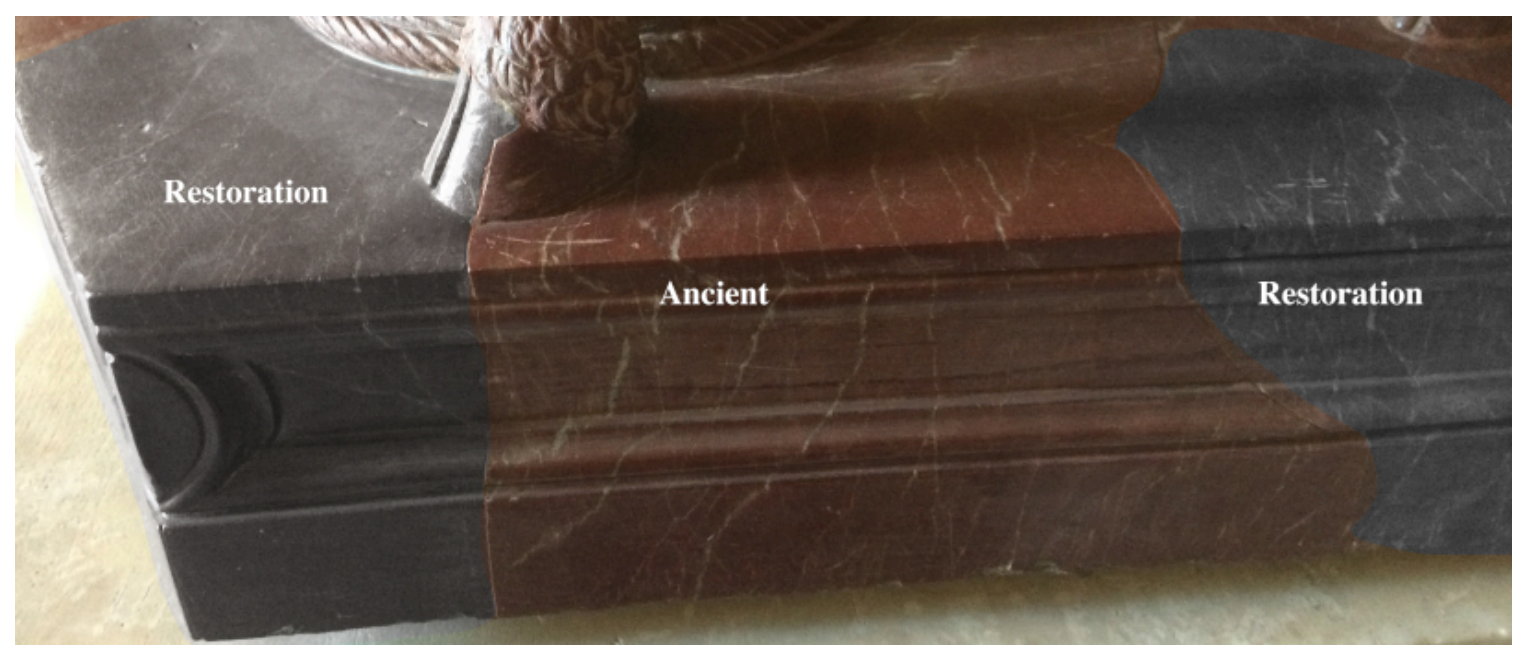

Figure 51. P-8: The left-side panel features an ancient fragment that also continues onto the ground of the plinth above. It appears to attach to the goat's left foreleg.

Further comments on the plinth: neither of the feet of the Red Faun is completely genuine. The ancient foot fragments do not appear to be attached, unbroken, to ancient parts of the base. This, in addition to Capponi's account, which tells us that the restoring sculptors were made to fashion a statue from a drawing in red pencil, casts considerable doubt on the disposition of the lower part of the figure. There are additional breaks and joins within the upper surface of the base, and the modern bits with grey veins surround the feet. Much of the base has the appearance of P-8, corroborating Capponi's records that roughly half the base is ancient.

\section{ANNOTATED 3DDM: PROCEDURE AND PROBLEMS}

The preceding catalogue was developed after much close observation of Robert Cohon's and the author's own photographs of the statue. The images attesting the condition just reported were uploaded to Flickr for eventual public viewing. A 3-dimensional digital model was elaborated photogrammetrically, and the photographs served as the annotations within the context of the model.

To make the photogrammetric model, Autodesk Recap was used. As not infrequently happens when photogrammetric models are made of highly reflective objects such as marble statues, the geometry of the mesh is dimpled, because the reflection of light off of the surface of the object is read by the software as a depression. This was true of the Red Faun. Before publishing the model online, then, the distorted geometry had to be fixed, smoothed, and extraneous geometry taken away. To do this, the model was brought into ZBrush for adjustment. After the surface imperfections were filled in and fixed, the number of polygons in the geometry had to be reduced to a fraction of the original in Zbrush in order to be quickly downloaded and used interactively on the web. To be sure, the reduction process decreases the detail of the geometry, but once the texture is mapped onto the model this difference is hardly noticeable. 
Finally, the geometry and related textures were uploaded into Sketchfab, a web service supporting interactive online publication of 3D models. The annotations were added in Sketchfab. Clicking on an annotation opens a dialogue box where the user finds a link to the appropriate Flickr image showing the annotated area in detail, along with its corresponding catalogue number. Because Sketchfab can generate an embed code for a 3DDM it hosts, the annotated model can be readily shared to social media, cited in an academic paper, or embedded on a website.

\section{CONSIDERING THE EVIDENCE}

This investigation has confirmed the trepidations of scholars who have expressed concern about the antiquity and authenticity of the Red Faun. The 3DDM and catalogue of observations reveals a more complicated picture of the eighteenth-century restoration by Cavaceppi and Bianchi than most scholarly catalogues have indicated, and, insofar as the sculpture is more fragmentary than imagined, it justifies the skepticism of scholars who worry about the integrity of the restoration. The attribution of the Red Faun as a Hellenistic sculpture should, then, be reconsidered in light of this investigation. This sculpture-and probably many like it that were restored in the eighteenth century-is an amalgam of the various personalities that were brought to bear on the stone. Thanks to the research of Barberini, who published Capponi's account, we can now understand it as an object that vibrates with the values and tensions of the characters-a pope, the excavators, a slew of other creative contributors-involved in bringing the Faun to its current state.

After a close reading of the full account of Capponi's involvement as published by Barberini, it seems that the restorers, Cavaceppi and Bianchi, merely brought to fruition the joint vision of Capponi and the painter in his employ, Salvatore Ettore. The circling questions of authenticity shift from relatively simple semantic issues of "copy" and "original," to understanding the statue as an expression of eighteenth-century excavation and restoration practices. It manifests its own history, as a work of art installed in Hadrian's richly appointed villa, as a deposited artifact, a scattered discovery, the object of restoration efforts, an exemplar of Hellenistic sculpture now gaily exhibited in the Capitoline Museums.

This new investigation and the 3DDM serve to inject the tangled history back into this sculpture. It allows for the parsing out of the various hands and cultural values that formed it, and calls for a different approach in classrooms and textbooks. Any further study of the Red Faun would do well to include these considerations, but the eighteenth-century restoration does not necessarily warrant the sculpture's dismissal from the canon of Hellenistic art history. The restorations should be noted with greater emphasis in surveys of classical sculpture for the purpose of highlighting the problems inherent in all of Hellenistic sculpture. This guise of wholeness is further alleviated by the annotated 3DDM.

Finally, this digital model serves as an invitation for others interested in the Red Faun to question the results of this preliminary study. Not all scholars will agree with the appraisal provided above, and more fundamentally some scholars will be diametrically opposed to our consideration of the documentary value of the artifact. We remind the reader that the 3DDM in this case study is meant to facilitate the faithful dissemination of condition reports, a document that considers only the material condition of the sculpture. 
Table 1. Appraisal of fragments by Barberini, ${ }^{8}$ Helbig, Jones, Howard, and Raeder

\begin{tabular}{l} 
"Trunk"/Torso \\
Head \\
Tip of left ear \\
Tip of nose \\
Chin \\
Lips \\
Slivers of hair \\
Fruit on nebris \\
Right arm \\
Left arm \\
Left hand \\
Pedum \\
Hanging nebris \\
Fold of goatskin on chest \\
Legs \\
Portion of feet \\
"Trunk" w/ Syrinx \\
Goat: Head \\
Goat: Left foreleg \\
Goat: hind legs \\
Goat: neck \\
Goat: tail \\
Goat: Body \\
Parts of plinth \\
Basket of Fruit \\
Number of observations \\
\hline
\end{tabular}

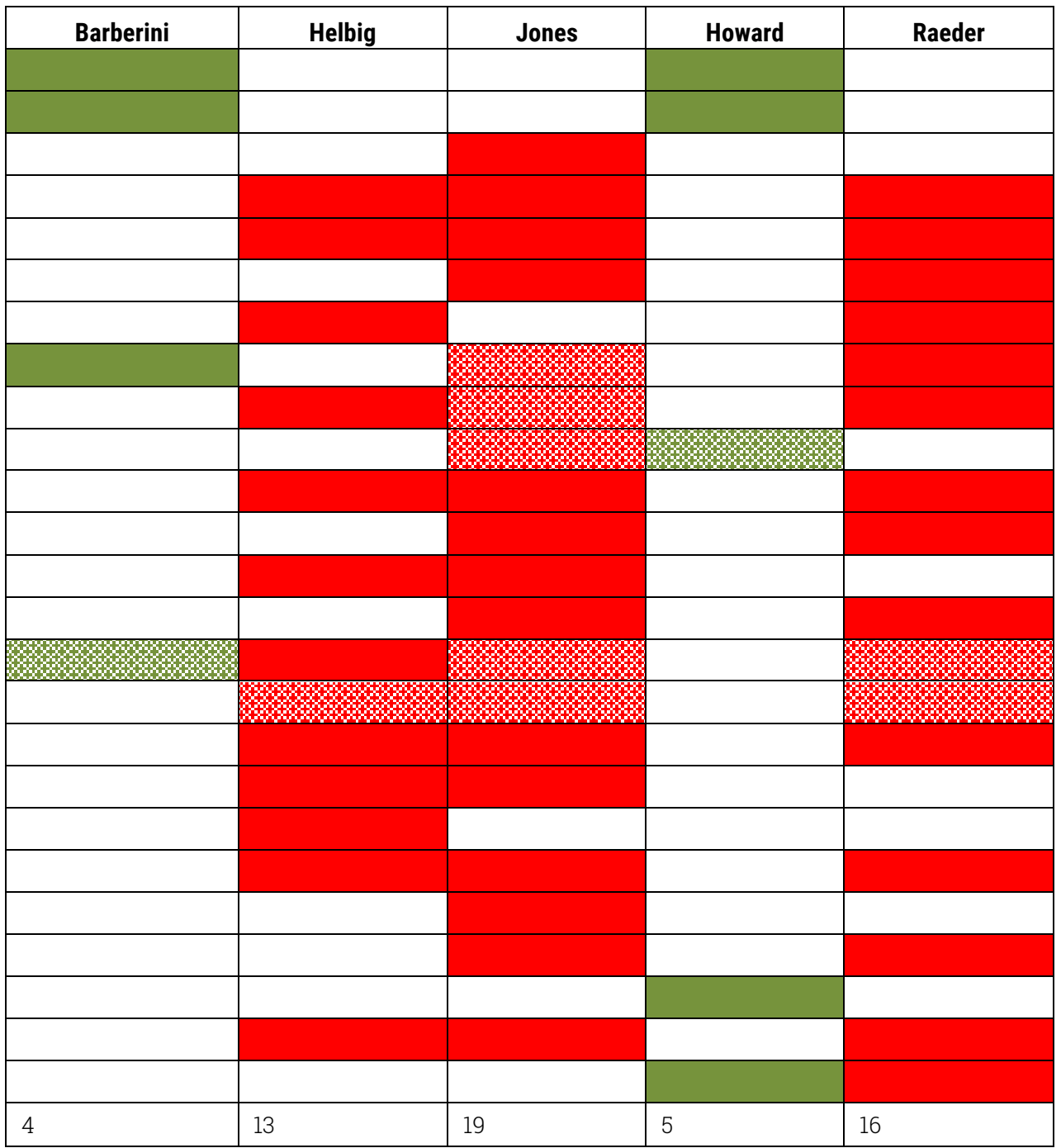

Antique
Antique (elaborated)
Modern
Modern (elaborated)

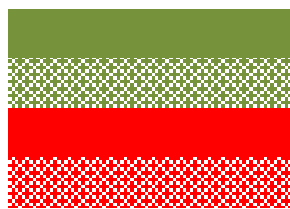

Aesthetic considerations should be brought to bear on the Red Faun in light of the evidence demonstrated here, but such an examination is beyond the scope of this paper and is better left to

\footnotetext{
${ }^{8}$ Note that Barberini reports on the account of Capponi [Barberini 1994].
} 
someone with the inclination. As the primary focus of this study, the interplay of close observation, new technology, and connoisseurship exists at the intersection of old and new methods within the traditional study of ancient art. It is in the best interest of bridging the gap between past and present that all the cognitive tools available in our time be utilized. By introducing the annotated 3DDM as a viable method for communicating condition reports, the field of study has opened for the remote study of a sculpture that has been hitherto known to most through low-contrast black-and-white photographs that disguise its duplicity. The free-access publication of the 3DDM will also serve as an educational tool for use in the classroom, freeing the instructor from the frustration of showing a single perspective of complex artifacts. Supplementing traditional written reports with intensive photographic evidence mapped onto the virtual sculpture will be practiced increasingly as the technology becomes more affordable and programs such as ZBrush and Recap 360 become a mainstay of conservation education. Until then, the procedure outlined above will allow the individual scholar to add to the corpus of web-published 3DDMs and thus to the catalogue of material available for interactive remote study. In this way, web-published models can only increase the visibility of and interest in museums, art history, and archaeology, and this is an advantage against which few would argue.

\section{ACKNOWLEDGMENTS}

All photographs in this article were taken by Robert Cohon at the Nelson-Atkins Museum of Art while the Red Faun was on loan from the Capitoline Museums in the summer of 2013. They are published here with the kind permission of Dr. Cohon and the Capitoline Museums. The author takes this opportunity to express her deep gratitude to Robert Cohon for so generously sharing the photographs with her. Many thanks are also due to the anonymous reviewers and to Matthew Brennan, Charlotte Forstall, Georgios Doudalis, Julie Van Voorhis, Bernard Frischer, and Diamantis Panagiotopoulos for each of their various contributions to this work, whether by providing technical support, reading various drafts, or lending keen observations.

\section{BIBLIOGRAPHY}

Francesco Paolo Arata. 1993. Carlo Antonio Napolioni e Clemente Bianchi. Bollettino Musei Comunali di Roma 7, 23-32.

Bernard Ashmole. 1961. Forgeries of Ancient Sculpture: Creation and Detection. The First J. L. Myres Memorial Lecture, Oxford, Blackwell, 3-15.

Maria Giulia Barberini. 1993. De lavori ad un fauno di rosso antico, ed altre sculture del Museo Capitolino, 1736-1746: Alessandro Gregorio Capponi, Carlo Antonio Napolioni e Clemente Bianchi. Bollettino dei musei comunali di Roma 7, 23-35.

Maria Giulia Barberini. 1994. La vita di Bartolomeo Cavaceppi. In Bartolomeo Cavaceppi scultore romano (1717-1719), Rome: Palombi.

Maria Giulia Barberini and Carlo Gasparri, eds. Bartolomeo Cavaceppi scultore romano (1717-1719), Rome: Palombi.

Elizabeth Bartman. 1991. Sculptural Collecting and Display in the Private Realm. In E. K. Gazda, ed. Roman Art in the Private Sphere: New Perspectives on the Architecture and Décor of the Domus, 
Villa, and Insula, Ann Arbor: University of Michigan Press, 71-88.

Clive Bell. 1949. Art, London: Chatto and Windus.

Walter Benjamin. 1968. The Work of Art in the Age of Mechanical Reproduction. In H. Zohn, trans. and H. Arendt, ed. Illuminations: Essays and Reflections, New York: Schocken, 217-252.

J. Dallaway. 1800. Anecdotes of the Arts in England or Comparative Observations on Architecture, Sculpture, \& Painting, Chiefly Illustrated by Specimens at Oxford, London: Cornmarket Press, 272-73.

Robert M. Entwistle. 2008. Digital Condition Reports. In Icon: The Institute of Conservation 3 January 2008. Web < http://icon.org.uk/system/files/icon_news_14_january_2008.pdf>. Last accessed January 27, 2016.

Bernard Frischer. 2015. Three-Dimensional Scanning and Modeling. In Elise A. Friedland and Melanie Grunow Sobocinski with Elaine K. Gazda, eds. Oxford Handbook of Roman Sculpture, New York: Oxford University Press, 74-87.

Wolfgang Helbig. 1891. Führer durch die öffentlichen Sammlungen klassischer Althümer in Rom (Band 1): Die vatikanische Skulpturensammlung die kapitolinischen und das lateranische Museum, Leipzig: Verlag von Karle Baedeker.

Seymour Howard. 1982. Bartolomeo Cavaceppi, Eighteenth-Century Restorer, New York, Garland.

Seymour Howard. 1991. Ancient Busts and the Cavaceppi and Albacini Casts. In Journal of the History of Collections 3.2, 199-218.

Stuart H. Jones. 1912. A Catalogue of the Ancient Sculptures Preserved in the Municipal Collections of Rome: The Sculptures of the Museo Capitolino, Oxford; rpt. Rome 1969: L'Erma di Bretschneider.

William Macdonald and John Pinto. 1995. Hadrian's Villa and Its Legacy, London: Yale University Press.

Maura Masini. 2014. Il restauro. Studi e restauri, Firenze: Ed. Polistampa, 53-55.

Pär Meiling, Gerold Esser, Norbert Pfeifer, Jan Rosvall. 2011. Optical Documentation Techniques for Condition Assessment of Facades: A Tentative Evaluation of Three Case Studies Executed in Götenborg and Vienna. In International Journal of Architectural Heritage, 5, 123-139.

Helen Nodding, Victoria Oakley, and Sandra Smith. Streamlining Condition Reporting: A New Approach at the Victoria and Albert Museum. In Icon: The Institute of Conservation 18 September 2008. Web. < http://icon.org.uk/system/files/icon_news_18_september_2008.pdf>. Last accessed 16 December 2015.

C.S. Patterson and K. Trentelman, eds. 2013. Integrating Imaging and Analytical Technologies for Conservation Practice: Report of an Experts Meeting Held September 10 - 12, 2013. (Los Angeles: Getty Conservation Institute, 2013). Web.

$<$ http://www.getty.edu/conservation/our_projects/integrating_imaging.html>. Last accessed 2 August 2017.

Yosi Posilev. 2011. The iPad: Condition Reporting for the XXI Century. Western Association for Art Conservation Newsletter vol. 33 no. 1 (Jan. 2011), 11-13.

Nicholas Stanley Price, M. Kirby Talley Jr., and Alessandra Melucco Vaccaro, eds. 1996. Historical and Philosophical Issues in the Conservation of Cultural Heritage, Los Angeles: The Getty Conservation Institute.

Joachim Raeder. 1983. Die statuarische Austtatung der Villa Hadriana bei Tivoli, Frankfurt am Main; 
Bern: Lang.

Nancy H. Ramage. 2003. Cavaceppi and Modern Minimalism: The Derestoration of Roman Sculpture. In M. Kunze and A. Rügler, eds. Wiedererstandene Antike, Munich: Biering and Brinkmann, 167-170.

Nancy H. Ramage. 2002. Restorer and Collector: Notes on Eighteenth-Century Recreations of Roman Statues. Memoirs of the American Academy in Rome. Supplementary Volumes, 1, Ann Arbor: University of Michigan, 61-77.

Alois Riegl. 1903. Moderne Denkmalkultus: sein Wesen und seine Entstehung, Vienna: W. Braumüller.

R.R.R. Smith. 1991. Hellenistic Sculpture, London: Thames and Hudson.

M. Kirby Talley. 1996. Introduction to Part 1. In Nicholas Stanley Price K. Kirby Talley Jr., and Alessandra Melucco Vaccaro, eds. Historical and Philosophical Issues in the Conservation of Cultural Heritage, Los Angeles: The Getty Conservation Institute, 2-42.

Melvin J. Wachowiak and Basiliki Karas. 2009. 3D Scanning and Replication for Museum and Cultural Heritage Applications. Journal of the American Institute for Conservation, vol. 48, no. 2 , 141-158.

Heinrich Wölfflin. 1950. Principles of Art History: The Problem of the Development of Style in Later Art. M. D. Hottinger, trans. New York: Dover; originally published as Kunstgeschichtliche Grundbegriffe: Das Problem der Stilentwickelung in der neueren Kunst (Munich: F. Bruckmann, 1915).

Received October 2016; revised September 2017; accepted November 2017. 